\title{
Olfaction in the context of Obesity and Diabetes: insights from animal models to humans
}

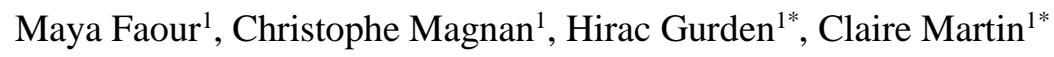 \\ 1 Université de Paris, BFA, UMR 8251, CNRS, F-75013 Paris, France. \\ *Corresponding authors.
}

\section{Highlights}

- Olfaction and feeding behaviors are tightly connected.

- Olfactory functions are impaired in obesity and type 2 diabetes both in humans and animal models.

- Decreased olfactory sensitivity could be due to hormonal and nutrients variations, inflammation, and reward system changes.

- Bariatric surgery rapidly restores olfactory sensitivity in anosmic morbid obese patients.

\begin{abstract}
The olfactory system is at the crossroad between sensory processing and metabolic sensing. In addition to being the center of detection and identification of food odors, it is a sensor for most of the hormones and nutrients responsible for feeding behavior regulation. The consequences of modifications in body homeostasis, nutrient overload and alteration of this brain network in the pathological condition of food-induced obesity and type 2 diabetes are still not elucidated. The aim of this review was first to use both humans and animal studies to report on the current knowledge of the consequences of obesity and type 2 diabetes on odorant threshold and olfactory perception including identification discrimination and memory. We then discuss how olfactory processing can be modified by an alteration of the metabolic homeostasis of the organism and available elements on pharmacological treatments that regulate olfaction. We focus on data within the olfactory system but also on the interactions between the olfactory system and other brain networks impacted by metabolic diseases.
\end{abstract}

Keywords: anosmia, diet-induced obesity, hyposmia, metabolic regulation, olfactory bulb, olfactory mucosa, type 2 diabetes 


\section{Abbreviations}

AgRP neurons $=$ Agouti-Related Peptide-expressing neurons

$\mathrm{ARC}=$ arcuate nucleus

$\mathrm{BMI}=$ Body mass index

$\mathrm{BS}=$ bariatric surgery

$\mathrm{DIO}=$ diet-induced obesity

GLP-1 = Glucagon-like peptide-1

HFD = high fat diet

HFHSD = high fat and high sucrose diet

HOMA-IR = Homeostasic model assessment of insulin resistance

LOT $=$ lateral olfactory tract

$\mathrm{MOB}=$ main olfactory bulb

MMSE $=$ Mini-Mental State Examination

$\mathrm{M} / \mathrm{T}=$ mitral and tufted

NPY = Neuropeptide $Y$

$\mathrm{OM}=$ olfactory mucosa

$\mathrm{ORN}=$ olfactory receptor neurons

$\mathrm{OT}=$ olfactory tubercle

$\mathrm{PCx}=$ piriform cortex

POMC $=$ Pro-opiomelanocortin

RYGB = Roux en-Y gastric bypass

$\mathrm{SG}=$ sleeve gastrectomy

SST $=$ Sniffin’ Sticks Test

$\mathrm{T} 2 \mathrm{D}=$ type 2 diabetes Mellitus

$\mathrm{TRPV}=$ transient receptor potential vanilloid ion channels

TDI = olfactory threshold (T) odor discrimination (D) and identification (I)

UPSIT $=$ The University of Pennsylvania Smell Identification Test 


\section{Introduction}

\subsection{Metabolic disease and food intake}

Metabolic diseases are driven by a combination of genetic predisposition and environmental factors. They eventually result in a dysregulation of energy balance driven by a reduced energy expenditure failing to compensate for enriched calorie intake. Obesity is a chronic relapsing disease characterized by a dysfunction of the biological system that regulates energy balance (Box 1). The prevalence of overweight and obesity is constantly increasing in Western countries (Czernichow et al., 2021) and it is suggested that by 2030 nearly 1 in 2 adults in the United States will be obese (Ward et al., 2019). This disease has deleterious consequences on many physiological factors and is associated with cardiovascular diseases, musculoskeletal disorders and cancers (O'Neill and O'Driscoll, 2015). Obesity dramatically increases the risk of type 2 diabetes (T2D) since one major consequence of an ectopic accumulation of triglycerides is insulin resistance and glucose intolerance that can lead to chronic hyperglycemia when pancreatic $\beta$-cell dysfunction occurs (Chatterjee et al., 2017).

\section{Box 1}

\section{Obesity and Type 2 Diabetes Mellitus (T2D)}

Obesity, a chronic and relapsing disease, is a medical condition described as excess body weight due to adipose tissue expansion following triglyceride storage. In addition, ectopic accumulation of triglycerides outside adipose tissue and low-grade inflammation can lead to severe health problems by the functional impairment of major organs such as the pancreas, the liver, the heart and the brain. T2D, hypertension, dyslipidemia, cardiovascular disease, stroke, sleep apnea, gallbladder disease, gout, osteoarthritis as well as certain cancers are among the comorbidities associated with obesity. Two billion adults overweight, of those 650 million are considered to be affected by obesity (Body Mass Index $\geq 30 \mathrm{~kg} / \mathrm{m}^{2}$ ). $13 \%$ of the world's adult population ( $11 \%$ of men and $15 \%$ of women) were obese in 2016. The prevalence of obesity across the world nearly tripled since the 1970's and continues to rise (source: https://www.worldobesity.org/; https://www.who.int/news-room/factsheets/detail/obesity-and-overweight).

Type 2 Diabetes Mellitus (T2D) (90\% of all diabetes cases) is also known as insulin-resistant diabetes, non-insulin dependent diabetes, and adult-onset diabetes. It is characterized by a cascade of events, usually starting by the appearance of insulin resistance (due to ectopic storage of triglycerides and low-grade inflammation in insulin-sensitive tissues, such as liver and skeletal muscles) which leads to impaired glycemia regulation, to exhausted pancreatic beta cell function and insulin secretion and finally to chronic hyperglycaemia. T2D is a major cause of blindness, kidney failure, heart attacks, stroke and lower limb amputationT2D is most commonly diagnosed in older adults, but is increasingly seen in children, adolescents and younger adults due to rising levels of obesity ( $80 \%$ of individuals with T2D are obese), physical inactivity and poor diet. The number of people with diabetes rose from 108 million in 1980 to 422 million in 2014 with a prevalence rate of approximatively 4.4\% (source: https://www.diabetesatlas.org; https://www.who.int/newsroom/fact-sheets/detail/diabetes).

Metabolic causes of obesity include lipotoxicity of fatty acids per se chronically elevated in the blood, ectopic accumulation of triglycerides in the liver and skeletal muscles and also proinflammatory 
cytokines release from adipose tissue altogether leading to insulin resistance. However, obesity is also characterized by a bidirectional cross-talk between the brain and the periphery. Energy homeostasis regulation is supported by a large network of brain areas, including the brainstem, hypothalamus, and mesocorticolimbic structures, constantly monitoring the internal milieu through nutriment and hormone sensing. These parameters are integrated to generate adaptive food intake and autonomic/endocrine responses determining energy balance (Berthoud, 2004). However, these brain regions are highly susceptible to changes in peripheral signals in the context of obesity. As a result, many clinical studies showed an association between obesity and T2D and neurological impairments including structural effects with atrophy of brain regions, vascular and metabolism hypoactivity. Obesity impairs cognition and increases the prevalence of some neurodegenerative disorders such as Alzheimer's disease (O'Brien et al., 2017; Mattson, 2019). As described by (Herbert and Pollatos, 2014), obese individuals have a reduced interoceptive sensitivity to internal hunger and satiation signals. Hence, their food consumption and food preferences are mainly driven by external food related cues. Indeed, the metabolic control of energy balance is not restricted to the management of internal milieu but is rather embedded in a much larger set of functions from sensations to hedonic (Saper et al., 2002; Berthoud and Morrison, 2008). Food has potent reinforcing and motivational properties and feeding is associated with sensations and is influenced by the context. The evaluation of pleasure provided by food and the metabolic consequences of their ingestion requires learning to associate sensory features with nutritional properties. Therefore, sensory inputs are decisive cues in assessing whether a food is palatable, i.e. provides a pleasant sensation when consumed; or if a food could be harmful or poisonous. In this context, smell is one of the most relevant sensory cues predicting food characteristics and is likely to play a key role in food choice and consumption (Boesveldt and de Graaf, 2017). The relation between olfaction and food intake has been established early on (Le Magnen, 2001; Yeomans, 2006) but did not receive much attention in the context of metabolic diseases until recently.

Several diseases as well as normal aging can impair the sense of smell either partially (hyposmia) or totally (anosmia) (Boesveldt et al., 2017). Hyposmic or anosmic patients report a severe alteration of the quality of life. It is estimated that $5 \%$ of the population has altered olfaction. This number increases with age as more than $50 \%$ of the population aged between 65 and 80 years old show signs of olfactory impairment, increasing to up to 75\% above 80 years old (Landis et al., 2004; Doty and Kamath, 2014). We have relatively poor knowledge of the consequences of obesity and T2D on olfactory brain regions and olfactory processing. Even though this problem has been underestimated it is important to understand what are the factors associated with metabolic syndrome that could be responsible for olfactory dysfunctions. The objective of this review is twofold: $1 /$ to increase awareness on olfactory impairments related to metabolic disease to improve medical care; $2 /$ to propose that probing olfactory function could be used as an early biomarker in clinics predicting the fate of energy metabolism disorders and cognitive impairments.

\subsection{Flavor, smell and food intake}

The flavor of food is determined by the cerebral integration of taste, chemesthesis and smell, 3 senses closely linked by the location of their receptors on the face, and their convergent pathways and integration in the brain. Taste (sweet, salty, bitter, sour and umami) is detected by buds located on the tongue. Chemesthesis, is the activation of the somatosensory system by chemical stimuli. It relies on the activation of the trigeminal nerve which innervates the tongue, the olfactory epithelium, and also the main olfactory bulb (MOB) via a family of transient receptor potential vanilloid (TRPV) ion channels (Brand, 2006). For instance, the activation of the trigeminal nerve is responsible for the freshness of mint or the heat of spices. Finally, the sense of smell is predominant in the evaluation of flavor and determines all its richness and finesse: many people experiencing anosmia report a loss of "taste" even though the gustatory system remains fully functional. 


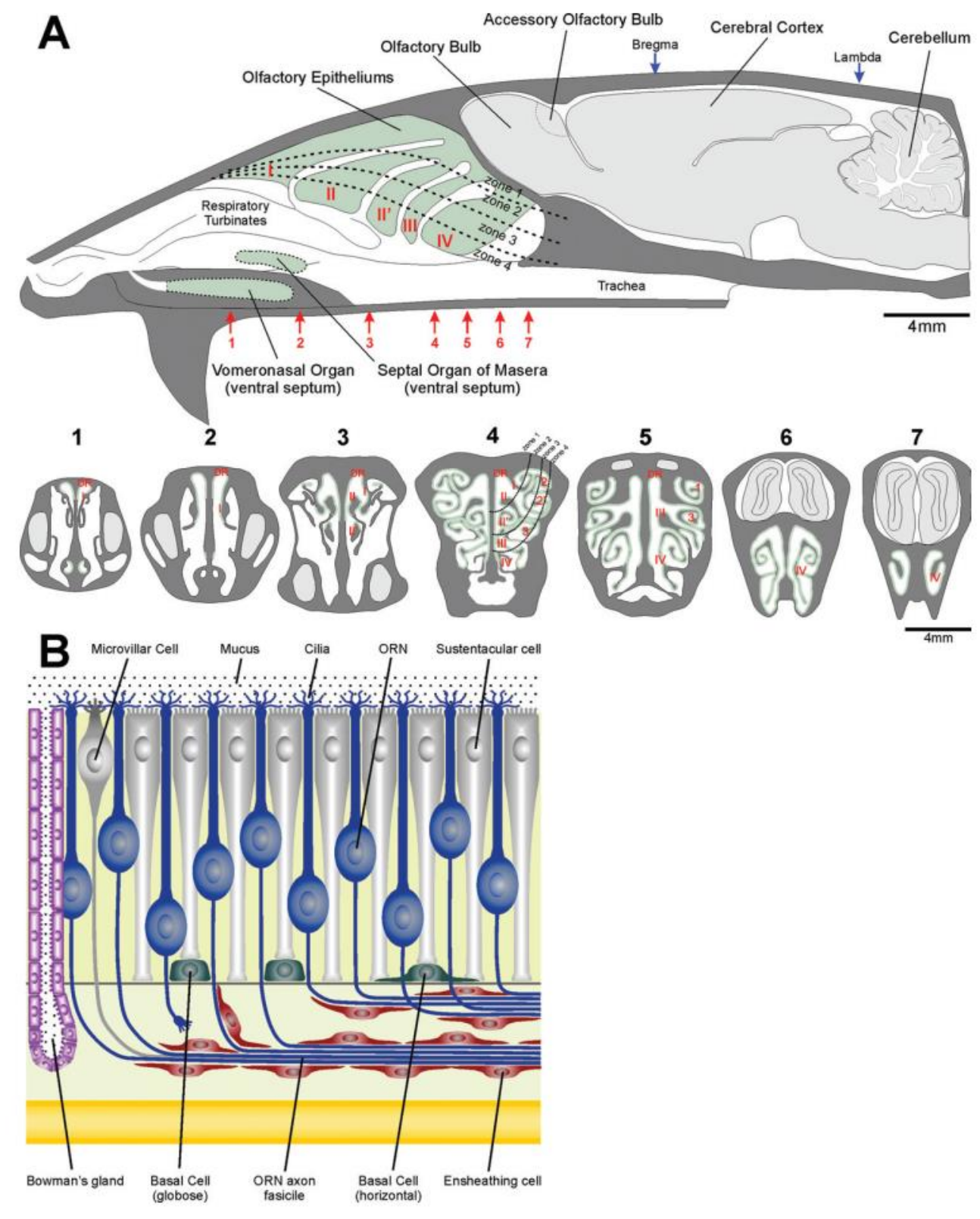

\section{Figure 1}

Diagram of the rat nasal cavity and brain shown in a lateral view and cross section diagrams through the nasal cavity at the location of the arrows. The main sensory epithelium is divided into four zones on the basis of the expression of different odorant receptor genes. Dashed lines show these approximate positions of these zones in the adult. Two other smaller regions of sensory neuroepithelium are present within the nasal cavities: the septal organ of Masera and the vomeronasal organ. (B) Schematic illustration of the olfactory epithelium showing the major cell types present in the rat epithelium. Reproduced from (Shipley et al., 2004) with permission from Pr Adam C. Puche.

Olfaction is a chemical sense, which means that odorants are only perceived if there is physical contact between the olfactory receptor neurons (ORN) of the olfactory mucosa $(\mathrm{OM})$-located in the superior part of the nasal cavity- and the odor molecules carried by breathing (Firestein, 2001). The inner recesses of the human nasal cavity, defined laterally by three pairs of turbinates (or conchae) and medially by the nasal septum that bisects it, is lined by a mucous membrane called the respiratory mucosa (Moran et al., 1982)(figure 1). Human respiratory and olfactory mucosa present distinct anatomo-functional features, 
especially because the $\mathrm{OM}$ is the only (very small) region containing ORN (figure 2B). Inspiration captures molecules in the ambient air and conveys them to the OM through the orthonasal pathway, expiration allows odorants present in the mouth and released by chewing, to reach ORN via the retronasal route. There are about 400 different types of receptors on the surface of ORN in humans. Each receptor can recognize several molecules, and each odorant can activate several receptors. Because of its organization the olfactory receptor system has an extensive ability to decode odorant traits (Mori and Sakano, 2011; Mainland et al., 2014; Kurian et al., 2021). Projections from the ORN converge and form the olfactory nerve (cranial nerve I) that crosses the cranial bone at the level of the ethmoid bone. The olfactory information is then processed by the projection cells of the MOB (mitral and tufted (M/T) cells; figure 2AC) at the level of the olfactory glomerulus, a functional module responsible for modulating the signal from the receptors (figure 2C). M/T cells directly project through the lateral olfactory tract (LOT) to brain regions identified as the olfactory cortex, including the piriform cortex (PCx) the anterior olfactory nucleus and the olfactory tubercle (OT), but also the entorhinal cortex and the anterior and posterolateral cortical amygdala (Price, 1985)(figure 3). The absence of thalamic relay and the anatomical proximity with the limbic system confer a unicity in the organization of the olfactory circuits explaining why the sense of smell is imprinted by emotions, has a unique evocative power, and is characterized by robust and lasting memory capacity (Uchida et al., 2014). Except for the OT, structures of the primary olfactory cortex project back to the MOB by sending centrifugal fibers through the LOT to the granular and the glomerular layers (Matsutani and Yamamoto, 2008; Padmanabhan et al., 2019; Zandt et al., 2019): these forward-feedback loops conveyed by the LOT are essential for olfactory processing and memory.

A

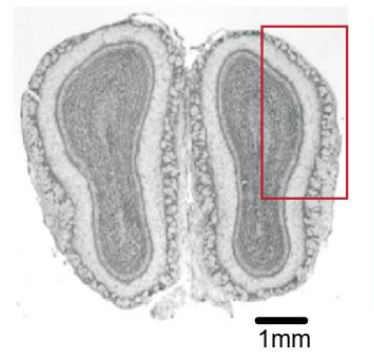

B
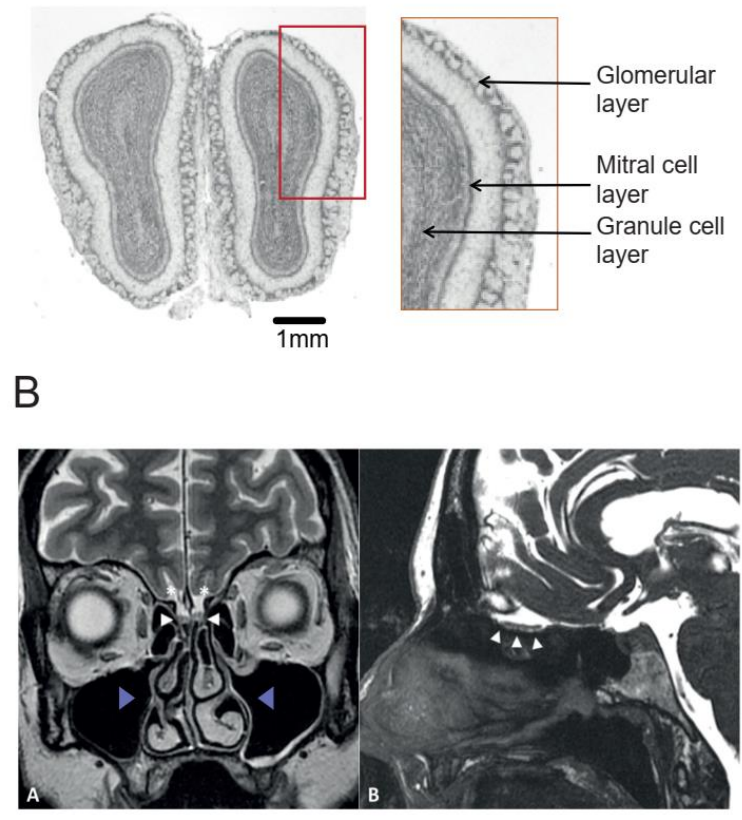

C

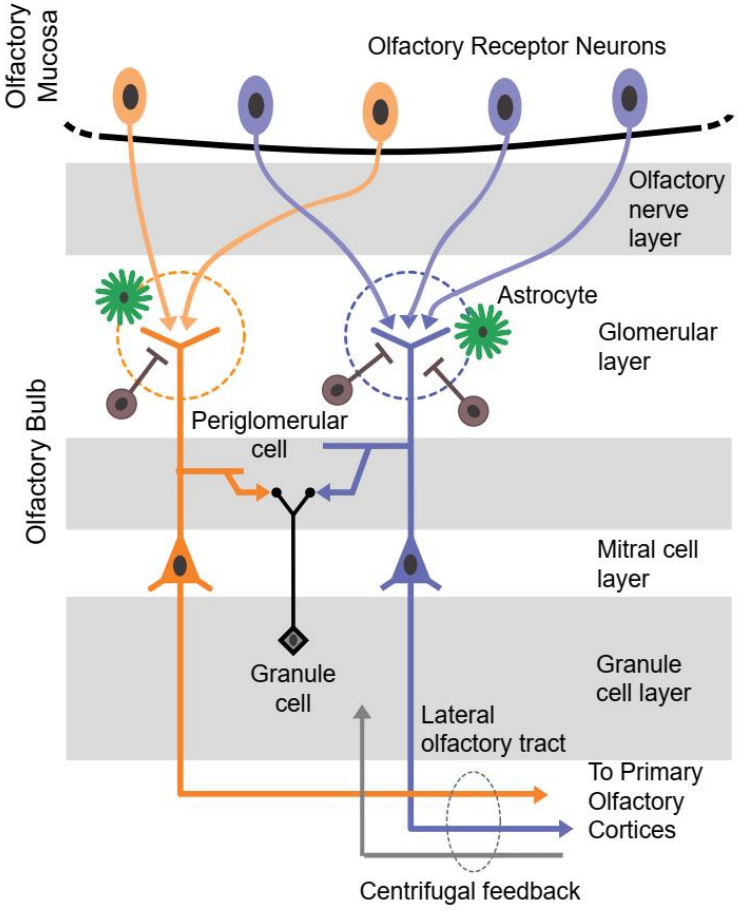

\section{Figure 2}

A: Coronal section of the adult main olfactory bulb in the rat. B: MRI of normal-size olfactory bulbs (white arrowheads) on coronal T2-weighted imaging (left) and sagittal Fast Imaging Employing Steady-state Acquisition, FIESTA (right). Turbinates of the nasal cavity are also observed (blue arrowheads). With permission from (Braun et al., 2019). C: Organization of the main olfactory bulb in rodents. In the olfactory mucosa, olfactory receptor neurons which express the same odorant receptor converge onto the same glomeruli in the MOB. Olfactory glomeruli located at the surface of the MOB enclose the synapses between the olfactory sensory neurons and the M/T cells, principal output cells 
(glutamatergic) of the structure. Granule and periglomerular cells (GABAergic interneurons) and glial cells (astrocytes) modulate olfactory information processing. Centrifugal fibers are constituted of inputs from the primary olfactory cortex and the neuromodulatory nuclei (noradrenaline, acetylcholine, serotonine). They contact granule and periglomerular interneurons.
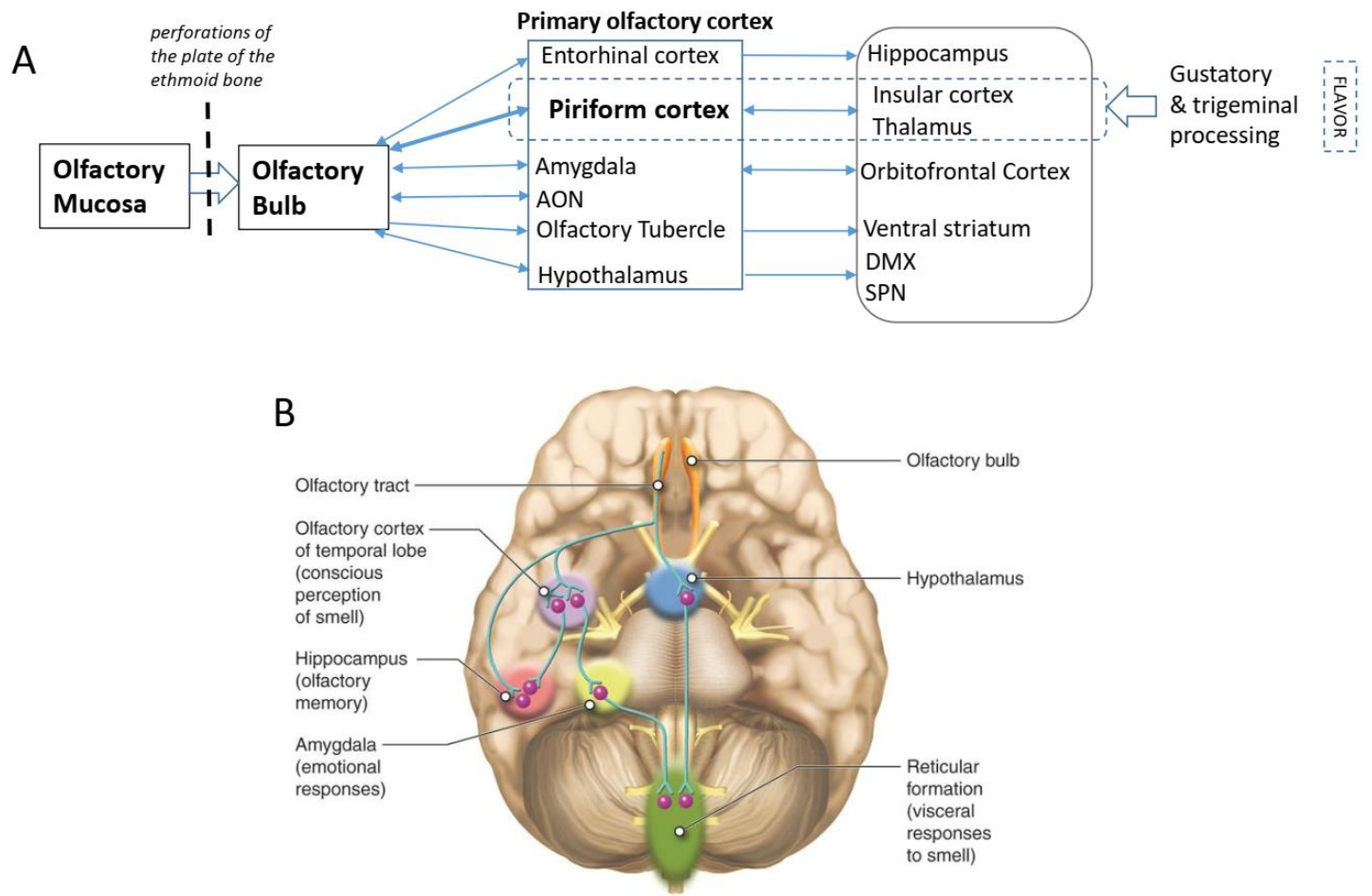

\section{Figure 3}

A: Diagram of the neuroanatomical connections within the olfactory pathways. AON: Anterior Olfactory Nucleus. DMX: dorsal motor nucleus of the vagus nerve. SPN: sympathetic preganglionic neurons. Dorsal B: Ventral aspect of human brain, in colors are brain regions that receive information from the main olfactory bulb. This work by Cenveo is licensed under a Creative Commons Attribution 3.0 United States (http://creativecommons.org/licenses/by/3.0/us/).

\subsection{Bidirectional modulation between olfaction and food intake regulation}

Even though it is recognized in humans that smell strongly influences appetite and satiety (Yeomans, 2006), the crosstalk between olfaction, food intake and energy metabolism in physiological conditions is still largely unknown.

First, seemingly to the hypothalamus, the MOB is highly sensitive to modulation by hormonal signals related to metabolism and food intake. In this structure, the blood-brain barrier is more permeable than in other brain regions, and the density of blood capillaries in the superficial layers of the MOB, at the level of the glomeruli is particularly high (Ueno et al., 1991; Lecoq et al., 2009). In addition, the olfactory system (OM, MOB and $\mathrm{PCx}$ ) express high levels of receptors for the main peptidergic and hormonal factors that accompany energy homeostasis, whether they are orexigenic (promote food intake) or anorexigenic (inhibit food intake). Many arguments suggest that the MOB in addition to processing odors can be considered as a metabolic sensor (see for a review Palouzier-Paulignan et al., 2012). 
Second, recent studies gathered evidence that odorants influence brain areas regulating food intake and energy expenditure and particularly the hypothalamus. This structure, primary integrator of circulating signal of hunger and satiety, contains autonomic neurons that regulate sympathetic and parasympathetic outflow (Luquet et al., 2010; Sladek et al., 2015). Chen et al. showed that in fasted mice, the mere presentation of food (and not its ingestion) has the same effect on the activity of the neurons of the arcuate nucleus (ARC) than the presence in the circulation of nutrients or hormones related to food intake. Food odorants inhibit Agouti-Related Peptide-expressing (AgRP) neurons and activate proopiomelanocortin (POMC) neurons within seconds. Contrary to predictions, this result shows that sensory cues previously associated with food by animals (particularly its smell and sight) are processed by neurons of the ARC as a real-time information on the availability of food in the environment (Betley et al., 2013; Chen et al., 2015). Direct projections from the MOB to the ARC (Russo et al., 2018) could be involved in this connection albeit pathways from the MOB to the hypothalamus are still not clarified (Price et al., 1991; Garrison and Knight, 2017). There is no evidence for a direct projection from the ARC to the olfactory system but both POMC and AgRP neurons project onto orexin neurons located in the lateral hypothalamus, and interestingly these neurons have a direct projection to the MOB (Peyron et al., 1998; Shibata et al., 2008; Schneider et al., 2020). Moreover, cholinergic neurons of the basal forebrain have recently been found to have a powerful role in modulating feeding behavior (Herman et al., 2016), and could also be involved in the variation of olfactory perception. In mice, optogenetic stimulation of the basal forebrain glutamatergic projections to the lateral hypothalamus elicited both hypophagia and a potent food-odor avoidance behavior (Patel et al., 2019).

Third, odorants are the most powerful distal cues to evaluate food palatability and hedonic content. Early work by Jacques Le Magnen in the 1960's examined the influence of odors on food palatability and introduced the notion sensory specific satiety. When he fed rats with odorized food for 2 hours every day, he noticed that rats consumed 2 to 3 times more food when differently odorized food were presented in succession compared to the same amount of food associated with a single odorant (Le Magnen, 1956, 2001). Indeed, the same odorant can be very appetizing on an empty stomach, acquire lower pleasantness after consumption and even become completely repulsive at satiety. But this affects specifically the consumed odorant (Cabanac and Duclaux, 1973; Duclaux et al., 1973; Rolls et al., 1981; Le Magnen, 2001). Then, the olfactory system came into focus as an important contributor to unintentional weight gain (Morquecho-Campos et al., 2020). Given that olfactory signals are perceived before food consumption (orthonasal route), food odor exposure has been shown to enhance sensory-specific appetite (McCrickerd and Forde, 2016; Boesveldt and de Graaf, 2017), initiate cephalic phase responses (Ferriday and Brunstrom, 2011) and even increase meal sizes (Ferriday and Brunstrom, 2008) and calorie intake.

To summarize, the olfactory system, the hypothalamus and mesocorticolimbic circuits form an integrative network for the regulation of energy metabolism and food intake. This network is deeply impacted by metabolic syndrome and specifically obesity and fat and carbohydrate enriched food consumption. However, the outcomes of metabolic syndrome on olfaction are still unclear. Until recently, olfactory testing lacked the proper standardization necessary to have an overview of olfactory characteristics linked with metabolic diseases. In the past few years, an increasing amount of data have been gathered on this topic. In parallel, studies of the link between olfaction and food intake in animal models have also expanded, arguing that the olfactory system is at the crossroad between sensory processing and metabolic sensing (Palouzier-Paulignan et al., 2012). Here we review evidence in humans and in rodents of the cost of energy rich food intake leading to metabolic diseases and its associated deleterious impact on olfactory processing. 


\section{Characteristic of olfactory modifications in the context of metabolic diseases}

\subsection{Obesity and olfaction in humans}

Surprisingly enough, it is difficult to find a clear answer about the impact of obesity on olfactory ability and performances. Two systematic reviews are specifically focused on psychophysics evaluation of olfaction in obesity (Islam et al., 2015; Peng et al., 2019). As pointed by (Islam et al., 2015), a lot of studies have technical limitations regarding the lack of sample power, the gender balance, the age of the patients, accurate control groups and the procedures used to scale smell. With improvement of procedures used to test olfaction, and the increasing number of studies taking smell into account, more data are available on changes in olfactory processing in obese individuals.

\subsubsection{Clinical Olfactory Tests}

Different tests have been used in clinical studies, we will focus our review on the 3 main and standardized tests. In the last decade, the "Sniffin' Sticks" test (SST) has become the most widely used tool for assessment of orthonasal olfactory performance, based on pen-like odor dispensing devices (Hummel et al., 1997). It assesses three subtests of olfactory function: olfactory threshold (T), odor discrimination (D) and odor identification (I), the sum of the results for the three subset being the "TDI" score. Odorant detection measure the lowest concentration of odorant detected by the subjects; the discrimination assesses if the subject can distinguish between different odorant compounds. Alteration on both parameters reflect an alteration of olfactory function, but discrimination can be impacted with an intact detection threshold. The identification is the ability to name an odorant from a list of 4 alternatives for each odor. Based on obtained TDI score, functional anosmia is defined as a TDI score $\leq$ 16.5, normosmia as a TDI score $>30.5$ and hyposmia as a score between these two values. The University of Pennsylvania Smell Identification Test (UPSIT) is another commonly-used test. Participants are required to identify the smell of 40 "scratch-and-sniff" microencapsulated odorant strips from a forced choice of 4 possible answers. The total number of smells correctly identified is normalized by age and sex (Doty et al., 1984; Joseph et al., 2019).

As described previously, odors are perceived through two classic pathways: via the nostrils, during sniffing, referred to as orthonasal olfaction, and via the mouth, during eating and drinking, referred to as retronasal olfaction. The perceived smell of food is based on the interaction between these two pathways (Bojanowski and Hummel, 2012). Contrarily to the tests described above the Candy Smell Test can test retronasal olfactory performances. It consists in placing a small candy with one target foodrelated aroma on the tongue. Subjects are then asked to suck or chew the candy and name the target aroma out of a list of four to five possible answers in a forced choice manner (Renner et al., 2009; Besser et al., 2020). After each candy, subjects must rinse their mouth with water. The maximal attainable test score is 21 for the applied 21-item version of the Candy Smell Test also known as 'Flavor Test' (Nettore et al., 2020). A total of 21 aromatics (including one blank, water) are administered. The flavor score (FS) is calculated as the sum of correctly identified aromatics and ranged from 0 to 21 . 


\subsubsection{Relation between orthonasal and retronasal olfaction and the BMI}

According to the World Health Organization (https://www.who.int/health-topics/obesity; 2021), overweight and obesity are defined as abnormal or excessive fat accumulation that may impair health. Body Mass Index (BMI) is a simple numeric measuring tool representing the weight in kilograms divided by the square of height in meters. An individual is considered overweighted when its BMI is comprised between 25 and $30 \mathrm{~kg} / \mathrm{m}^{2}$, a BMI above 30 falls in the obesity range and a BMI of 40 or higher is categorized as severe or morbid obesity.

Overall, pathologically high or low body weight or BMI is associated with reduced olfactory capacities. Aschenbrenner et al found that patients with eating disorders, such as anorexia nervosa or low weight bulimia nervosa $(\mathrm{BMI}<18)$, have lowered olfactory sensitivity that improved with increasing BMI (Aschenbrenner et al., 2008). Subjects suffering from severe obesity (BMI $>45 \mathrm{~kg} / \mathrm{m}^{2}$ ) are more likely to have olfactory dysfunction than moderately obese individuals (BMI $>30 \mathrm{~kg} / \mathrm{m}^{2}$ ), and elevated BMI is associated with a significantly increased olfactory thresholds (Obrebowski et al., 2000; Richardson et al., 2004; Simchen et al., 2006; Skrandies and Zschieschang, 2015; Fernández-Aranda et al., 2016; Fernandez-Garcia et al., 2017; Peng et al., 2019; Poessel et al., 2020b). Consistent results were reported in 2015 by (Patel et al., 2015) who found that $80 \%$ of individuals (19-85 years) with impaired olfactory performances were overweighted or obese. In middle-aged stage I-II non-diabetic obese patients (31 women, 29 men, 50-70 years; 30>BMI $>40 \mathrm{~kg} / \mathrm{m} 2$, with metabolic characteristics in the physiological range including normoglycemia after fasting), olfactory deficit is significantly prevalent (Campolo et al., 2021). If the BMI is a simple measure of obesity, it is also correlated with hormonal changes which could be the cause of olfactory impairment, but very few studies have controlled these parameters. The relation between hormonal levels and olfaction will be discussed in the section 3.1.

Flavor perception mostly relies on retronasal rather than orthonasal olfaction (Shepherd, 2006), but most of the studies investigating the effects of olfactory dysfunction on body weight essentially focused on orthonasal abilities, while only a few of them examined the retronasal odor perception. In a recent study conducted by (Besser et al., 2020), retronasal olfactory abilities were assessed in a group of 74 subjects (47 females, 27 males; 20-63 years) using the SST while retronasal olfactory functions were tested in a group of 66 subjects ( 42 females, 24 males; 20-59 years) using the Candy Smell Test. The author found that both orthonasal and retronasal olfactory abilities declined with higher BMI and suggested the need of further studies using established retronasal tests. A similar study by (Nettore et al., 2020), investigated retronasal olfaction using the Flavor test, a series of 20 aromatic extracts, in 420 subjects belonging to different BMI classes (276 females and 144 males, >18 years old; BMI 25.9 to 43.7). In those subjects, higher BMI inversely correlated with Flavor Score (FS): individuals with obesity had lower FS when compared to normal weight or overweight subjects. This effect was significant between 18 and 47 years old), whereas it was absent in older individuals ( $>47$ years old).

\subsubsection{Homeostatic and Hedonic regulation of olfaction in normal weighted vs obese individuals: discrepancy between food vs non-food odors}

It was hypothesized that the olfactory detection threshold was lower when hungry compared to being satiated, which would support the notion that a decrease in sensitivity is part of the food intake control mechanism. Older studies have shown that odor acuity was higher with higher degrees of hunger and that a meal was preceded by a period of decreased olfactory thresholds whereas a period of increased olfactory thresholds was observed after food intake (decreased sensitivity) (Goetzl et al., 1950; Hammer, 1951). However, available data are not consistent and it is still unclear whether the satiety or the circadian clock are responsible for olfactory acuity change over daytime (Koelega, 1994). These 
discrepancies are also confounding for studies in obese individuals. When using neutral odors, Stafford and Welbeck observed that olfactory sensitivity was indeed higher in the non-satiated versus satiated state, and that this difference was increased in high BMI group compared to the low BMI group (19-49 years) (Stafford and Welbeck, 2011). The authors did not show a difference in olfactory acuity in response to food odors in the satiated versus non-satiated state in a low BMI group. Nevertheless, the high BMI group had greater acuity for food odor in the satiated versus non-satiated state (Stafford and Welbeck, 2011). These data point to opposite effects in the relation between internal state and acuity for food and non-food odorants, and this effect is enhanced in obese individuals. Moreover, obese subjects (BMI>30; 18-24 years) were found to have higher sensitivity to odors with high hedonic value (pleasantness ratings) like chocolate odor (Stafford and Whittle, 2015). However, (Poessel et al., 2020b) used 3 different odors (n-butanol, chocolate and grass) in 75 young healthy participants (26 normal weight, 25 overweight, and 24 obese; 37 women; $18-35$ years). They found no significant interaction between the quality of odor (food vs. non-food), hunger state, and BMI. Thus when focusing on chocolate odor, they found that higher BMI is associated with an increase in odor sensitivity in the sated state, but only on metabolically healthy individuals (optimal Homeostasic Model Assessment of Insulin Resistance $($ HOMA-IR) $\leq 1)$. Although data are not sufficient to conclude, there may be a dysregulation of the modulation of central odor sensitivity with nutritional state in obese.

From a different perspective and at the other end of the hedonic spectrum, (Trellakis et al., 2011) found that pleasantness rates for the generally disliked odor of black pepper oil were significantly lower in obese compared with non-obese subjects (20-45 years). This implies that the association of an odor to bitter tasting foods of generally lower calorific value is more negative in obese versus non-obese individuals. Taken together, these findings show that obese individuals show increased sensitivity and preference for an odor associated with palatable energy dense foods.

\subsubsection{Effect of age and sex on olfactory performances in obese vs non obese individuals}

Nutrition is an important factor to consider in elderly people. Given that metabolic rate, energy intake, and macronutrient intake decrease with age, food selection can become critically important in maintaining energy balance (Wakimoto and Block, 2001). Age-related declines in various aspects of olfactory function have been documented and older individuals show higher olfactory detection thresholds: (Cain et al., 1990; Murphy et al., 2002).

Most adults gain weight between the third and the sixth decade of life. After the sixth decade, a moderate weight loss is observed (Addison and Ryan, 2018). In line with these physiological facts, (Simchen et al., 2006) found that in adults ( $<65$ years), an increasing body weight or BMI was associated with a lower odor identification and odor detection capacities. However, surprisingly, among elderly subjects (>65 years) higher relative body weight or BMI was associated with higher odor identification and odor detection abilities.

In addition to BMI and age, the subject's gender has been found to be associated with changes in olfaction. Within a normosmic population (85 males and 76 females; ages 19-95), women had better olfactory capabilities when compared to men of the same age (Ship et al., 1996). The effect of high BMI (obesity) on olfactory performances had been studied in both female and male groups but no study compared the interaction between BMI and gender on olfactory perception. Hence, further studies are needed to answer this question. 


\subsection{Type 2 diabetes and olfaction}

Changes in olfactory sensitivity were reported both in type 1 insulin-dependent Diabetes (mild hyposmia in T1D which is insulin-dependent but obesity-independent, (Yilmaz et al., 2019)) and T2D (Weinstock et al., 1993). Since most T2D patients are obese $(\sim 80 \%)$ and the pandemic of obesity explains the incidence and prevalence of T2D, we decided here to focus on smell function in T2D patients (Eckel et al., 2011). Indeed, a progressive rise in insulin resistance and a consequent progressive defect in insulin secretion makes the metabolic state of obese patients worsens slowly towards T2D (Box1).

Smell dysfunction in diabetes was first reported 60 years ago (Jørgensen and Buch, 1961): even tested roughly and only with coffee, 35 over 69 patients were found hyposmic and 7 anosmic. No gustatory problems were detected confirming the lack of dysgeusia previously reported in T2D subjects (Bonatti, 1950). Finally, no correlation between hyposmia and age or severity/duration of diabetes was observed but it was not indicated whether patients were T1D or T2D. Two excellent reviews thoroughly revisited studies dealing with the fate of olfaction in T2D patients from the 1960's (13 articles reviewed in (Zaghloul et al., 2018)) and with a further systemic analysis (11 articles reviewed in (Kim et al., 2019)). Although most of the studies have checked for the absence of any Ear, Nose and Throat (ENT) problems, results are controversial: some studies clearly found olfactory deficits while others describe only mild impairment of olfactory function or intact smell. Methodological issues on the poor follow-up of olfactory function (Jørgensen and Buch, 1961; Hawkins and Pearlson, 2011; Seraj et al., 2015) on one side and the imprecise description of the metabolic state of patients (for example T1D not distinguished from T2D in (Jørgensen and Buch, 1961; Patterson et al., 1966; Brämerson et al., 2004; Gascón et al., 2013) on the other seem to be the two major source of discrepancies. In addition, the correlation between BMI and smell defects in T2D observed by Naka et al. (2010) was not confirmed by Gouveri et al. (2014). However, if a classification of smell deficit is made according to the severity of T2D, results are more homogeneous: in fact, patients suffering from uncomplicated T2D had the least olfactory impairment (Naka et al., 2010) while accumulation of complications (retinopathy, neuropathy, hypertension...) was accompanied by profound hyposmia (Floch et al., 1993; Brady et al., 2013; Gouveri et al., 2014; Yazla et al., 2018; Catamo et al., 2021). In that sense, very recently, (Catamo et al., 2021) showed that $22 \%$ of 94 T2D patients had identification impairment in salt taste and $55 \%$ odor recognition (SST) compared to control subjects. In the same study, 65\% of hypertensive T2D subjects presented smell identification impairment compared to $18 \%$ of non-hypertensive patients underlying again the fact that T2D with complication strongly impairs olfaction. Micro- (retinopathy, Gouveri et al., 2014) and macro- (coronary artery disease and peripheral vascular disease with a likely ischaemic damage to the olfactory system, (Weinstock et al., 1993)) vascular damages were shown to be associated with poor olfactory scores and could contribute to the overall olfactory impairment described so far. Self-reported profound hyposmia was also observed for T2D patients on aggressive treatments including oral and insulin treatment, i.e. with higher severity, compared to those who reported no use of drug treatment (Chan et al., 2018). Like earlier, these authors did not find an association between diabetes duration and prevalence of olfactory dysfunction. However, noteworthy, in elderly populations (age 6877), altered olfaction in T2D patients was reported to be associated with cognitive decline (Sanke et al., 2014).

\subsection{Bariatric surgery and olfaction}

Laparoscopic bariatric surgery (BS) procedures are used to induce weight loss in patients with extreme, morbid obesity (BMI > 40). These techniques mainly consist in Roux en-Y gastric bypass (RYGB) and sleeve gastrectomy (SG) (Angrisani et al., 2015). RGBP involves cutting the stomach in two to create a pouch out of the smaller proximal portion of the stomach, attaching it to the jejunum, thus bypassing a large part of the stomach and all the duodenum. In SG, the stomach is reduced to about $1 / 3$ of its original size, by surgical removal following the major curve, leaving the stomach with a banana shape also called 
a "sleeve-like" shape. SG permanently reduces the size of the stomach. Both RYGB and SG induce rerouting of nutrients to the small intestine, directly and faster respectively. They allow significative improvement in weight loss outcomes and obesity-related comorbidities such as diabetes (Koliaki et al., 2017). They were shown to trigger profound changes in peripheral secretions, including the levels of key hormones involved in energy metabolism such as gut hormones ghrelin and GLP-1, leading to a lower weight set point (Moffett et al., 2021). Since it was observed that food preferences of obese patients after BS is significantly changed (Coluzzi et al., 2016), suggesting a modification of sensory perception, the influence of BS on chemical senses was explored recently. Since taste is not the focus of the present review, we advise to refer to the comprehensive reviews of (Nance et al., 2020) and (Ahmed et al., 2018) for the follow-up of gustatory performances after BS.

Using a semi-quantitative taste and smell questionnaire, (Graham et al., 2014) reported that in 104 patients (24-63 years) with RYGB, sensory changes in appetite, taste and smell were noted in 97, 73 and $42 \%$ of patients, respectively. With SST and focusing on morbidly obese patients, about $22.7 \%$ of the 44 patients were found hyposmic by Holinski and colleagues (Holinski et al., 2015), showing significantly lower TDI scores than healthy controls. The same percentage of this cohort (15 RYGB and 15 SG patients) presented dysgeusia probed with the taste strip test. Six months after BS, half of the hyposmic patients presented better olfactory function.

(Hanc1 et al., 2016) performed SST in 54 morbidly obese patients (19-57 years) before SG then patient's weight losses and TDI were estimated at first, third and sixth month post SG. Median TDI scores of the patients were significantly increased from 25 preoperatively to 32 in the first month, 37 in the third month, and 41 in the sixth month showing improvement in olfactory sensitivity in SG patients (as a reminder a TDI score $>30.5$ is the threshold for normosmia). (Jurowich et al., 2014) found a positive correlation between body weight loss and TDI scores after SG (15 patients) but not in 15 RYGB patients. In fact, some controversies exist on the higher impact of SG over RYGB on smell. First, SG patients showed no improvement in their olfactory function tested by SST (39 patients tested 24 hours post SG in (Pisarska-Adamczyk et al., 2021); 8 patients in (Enck et al., 2014)). In opposition, (Makaronidis et al., 2016) analyzed subjective appetite, taste, smell and food preferences before and after BS and reported olfactory improvement in $41 \%$ of the 98 RYGB patients compared to $28 \%$ of the $155 \mathrm{SG}$ patients. In addition, (Melis et al., 2021) recently reported that both SG (n=21) and RYGB ( $n=26)$ had positive effects on taste and smell (tested by SST recovery) after surgery. These discrepancies may be due to multiple methodological reasons ranging from the number of patients in the cohort (from a dozen to more than 100) to the success rate of BS. In fact, successful surgery in the long term is a crucial factor in sensory recovery and food preference changes (Guyot et al., 2021).

Surprisingly, changes in sensory sensitivity post-surgery could reach hyper-reactions leading to food aversions in patients who experienced more post BS weight loss and reduction in BMI (Makaronidis et al., 2016). (Graham et al., 2014) reported that $73 \%$ patients had aversion to specific foods after surgery, with meat products the most commonly cited. (Tichansky et al., 2006) also observed that many patients developed aversions to sweet foods and meats and that food preferences changed right after surgery (in $68 \%$ of 82 RYGB patients). Sensory aversion is a complex emotional reaction implicating at least the amygdala and the insular cortex (Miranda, 2012; Münzberg et al., 2015), two brain areas that receive massive olfactory information (Mainland et al., 2014). Extended effects of BS on the overall sensorylimbic networks should be studied by brain imaging techniques to give access to the brain activity underlying changes in olfactory aversion after surgery.

\subsection{Preclinical model of diet-induced obesity and olfaction}

Although most of the knowledge regarding impairment of olfaction in metabolic syndromes has been collected in humans, animal models are required to decipher the origin and mechanisms and to 
understand what is the biological substrate of olfactory defects. Diet-induced obesity (DIO) models are considered the most accurate in reproducing the multidimensional aspect of human obesity combining genetic and environmental factors. They are based on the fact that in rodents -as in human- the consumption of food enriched in fat (using diet having a different percentage of fat and sucrose content) is positively correlated with body weight gain and elevation of plasma glucose, cholesterol, triglyceride, free fatty acid, and leptin levels (Ghibaudi et al., 2002; Hariri and Thibault, 2010).

Numerous alterations in olfactory performances have been observed in diet-induced obesity (DIO) models in rodents. Behavioral testing shows that mice under high fat diet (HFD) have poorer olfactory performances. Lietzau et al have followed the evolution of olfactory performances during the development of obesity by comparing 3 groups of mice fed either with standard diet, HFD (54\% energy from fat, $29 \%$ from carbohydrate) or western diet (42\% energy from fat, $43 \%$ from carbohydrate). After 1 month of HFD or western diet, no difference in the olfactory performances was observed compared to a regular diet fed group. After 3 months of diet, the HFD group started to spend more time to find a buried food (a piece of a protein bar), and the difference was significant for the 2 groups (HFD and western diet) after 8 months of diet (Lietzau et al., 2020). Another study in mice revealed different outcomes according to the sensory properties of the food used in the test (Tucker et al., 2012b). Using a peanut butter cracker, whose odorant properties were close to the fat food used for the diet they obtain an increase of the time necessary to uncover the food. However, this impairment was abolished when a chocolate treat was buried. The authors suggest that the fat diet impaired the detection of fat related odorants. Moreover, the same test performed on a genetically obese strain MC4R-null mice fed on regular diet did not show olfactory impairment (Tucker et al., 2012b). However, they did not find impairment in the capacity of obese mice to discriminate between two fatty acids (oleic and linoleic acid) that represent a large proportion of the used diet when tested in the habituation dishabituation test. This is in agreement with the study by Lietzau, in which HFD mice were impaired in novel odor recognition paradigm but not in discrimination capacity in habituation dishabituation test. Interestingly, mice fed with western diet, enriched in carbohydrate and rather associated with T2D, were impaired earlier than mice fed on HFD, suggesting a higher impact on cognitive processes. On the opposite, using HFD (Takase et al., 2016) found that performances in a habituation dishabituation task were impaired for DIO mice. Moreover, a similar deficiency was found in mice fed with the same fat diet but whose quantity eaten was adjusted based on their body weight each day so that their body weights were kept similar to those of the chow diet group, i.e. in non-obese non-diabetic mice consuming low quantities of HF (Takase et al., 2016). Finally, when challenged in an olfactory go-no go operant conditioning paradigm, HFD (60\% fat) or mild FD ( $32 \%$ fat) fed mice failed to show good discriminatory performances compared to animals fed on chow diet (13\% fat). In addition, obese mice were not able to learn the reversal of the task rules (Thiebaud et al., 2014). However, the limitation of these tests is that the olfactory component is only partial, they rather involve cognitive functions such as flexibility and memory that are known to be impacted in obesity (Yang et al., 2018).

Findings on olfactory performances are similar in rat models. Lacroix et al 2015 compared the behavior of obesity-prone Sprague-Dawley rats fed with a high-fat/high-sucrose diet (HFHSD) with those of obese-resistant ones fed with normal chow. Obese rats also have poorer performances in finding a hidden almond cookie (Lacroix et al., 2015). After several consecutive days of testing, rats became more efficient to find the buried food, however this learning was affected in obese animals that did not improve their performances over time. On the other hand, when challenged in a conditioned odor aversion test, in which the animals have to choose between a bottle containing plain water or a bottle containing water odorized with the conditioning odor, obese rats drank less odorized water even for low odor concentration suggesting that they have an increased odor sensitivity. Authors also report modification in exploratory behavior. In lean rodents, the duration of exploration of a food odor is increased in fasted compared to fed animals (Prud'homme et al., 2009). However the difference according to the metabolic status is largely diminished in obese animals who spent less time sampling a food odor when fasted compared to lean controls (Badonnel et al., 2014; Lacroix et al., 2015). 
Interestingly, in the conditioned odor aversion test, the obese rats spent more time sniffing the bottles, odorized or not (Lacroix et al., 2015).

The consequences of T2D on olfaction have been assessed using the same tests (buried food and habituation-dishabituation) in the model of Goto-Kakizaki rats. The results recapitulated the clinical observations in humans with T2D showing an alteration of both olfactory detection and memory (Lietzau et al., 2018).

Taken together these data are in agreement with results obtained in humans that metabolic alterations negatively impact olfactory performances. Moreover, the choice of the odorant and the type of odorant (food or neutral odor) could affect the outcome of the tests, in agreement with the results presented above in humans ( $\mathrm{cf}$ 2.3.1). In addition, the use of precisely controlled food in rodents brings evidence suggesting that the energy content of food independently of the body mass or fat accumulation in the animals is a major contributor of olfactory defects, however, more studies are needed to support this hypothesis.

\section{What are the causes of olfactory defects related to metabolic diseases?}

Many hypotheses can be raised to explain how metabolic status and/or circulating nutrients concentration affect olfaction. Until recently, the human MOB was not accessible to functional imaging. Since it is now technically possible to use non-invasive technologies to examine this structure in patients, the field will expand (Fournel et al., 2020; Iravani et al., 2020). For now, most of the information we have on modification of the MOB functions by obesity of energy enriched food is provided by animal models. Even if studies on the consequences of obesity on the structures of the olfactory pathway are scarce, we can gain insight from the existing information on the link between the metabolic status and olfactory functions in physiological condition. As mentioned above, the olfactory system is strongly influenced by hormones and nutrients which regulation is profoundly altered in the context of obesity. For a complete review of the link between endocrine mechanisms and olfaction, the reader is referred to (Palouzier-Paulignan et al., 2012). We will mention here more recent results and hormonal changes related to obesity.

\subsection{Changes in hormone and nutrients levels can account for olfactory impairment}

\subsubsection{Insulin and glucose}

Obesity is characterized by the elevation of blood glucose and insulin resistance. Insulin, insulin receptors and the insulin dependent glucose transporter GLUT4 are found in olfactory regions, from the mucosa (Lacroix et al., 2008) to the PCx (Zhou et al., 2017; Al Koborssy et al., 2019), the anterior olfactory nucleus, and the OT (Hill et al., 1986). In the MOB, GLUT4 co-localized with IR insulin receptors in M/T cells and glomeruli (Julliard et al., 2017). Moreover, the MOB is the area of the central nervous system containing the highest concentration of insulin (Baskin et al., 1994), the highest concentration of insulin receptors (Hill et al., 1986) and the highest rate of degradation (Banks et al., 1999). Insulin transport through the blood brain barrier at the level of the MOB is 2 to 8 times faster than for other regions of the brain (Banks et al., 1999). Interestingly, using extracellular fluid glucose concentrations measured in the MOB of Zucker leptin-receptor-deficient rat (fa/fa), Aimé et al, 2014 reported that the MOB contained twice the amount of glucose found in the cortex, and in both regions, the values are 2 -fold higher in obese fa/fa compared to lean rats. Finally, M/T cells in the MOB are 
responsive to glucose concentration (Tucker et al., 2010; Aimé et al., 2014; Al Koborssy et al., 2014) and express molecular hallmarks of glucose sensing cells (Julliard et al., 2017). Taken together, these elements add to the hypothesis of the MOB as a metabolic sensor.

In obese Sprague-Dawley rats fed with HFHSD, the number of insulin receptors in the MOB is decreased (Lacroix et al., 2015). However, the lack of sensitivity to insulin in DIO mice could also be explained by the physiological properties of the M/T cells of the MOB. In lean mice, insulin application enhances $\mathrm{M} / \mathrm{T}$ cell excitability by increasing neuronal firing activity of $\mathrm{M} / \mathrm{T}$ cells and decreasing interspike interval (Savigner et al., 2009; Fadool et al., 2011; Kuczewski et al., 2014). In DIO animals, the basal firing pattern of $\mathrm{M} / \mathrm{T}$ cells is altered, formed by shorter action potential clusters separated with long pauses. In this condition, acute insulin stimulation dampened M/T cell modulation observed in lean animals (Fadool et al., 2011).

In obese and lean young women (18-35 years), (Poessel et al., 2020b) measured insulin reactivity in response to food intake and found that insulin resistance was negatively correlated with food-related odorant (chocolate) independently of BMI. In elderly human population (>50 years), it was shown that insulin resistance (but not fasting blood glucose, glycohemoglobin or serum insulin levels) was linked to an increased risk of olfactory defect (Min and Min, 2018). Chronic administration of insulin in rodents was used as a way to recapitulate the insulin elevation in obese individuals. However, in mice models, long-term administration of insulin delivered intranasally did not affect olfactory behaviors, energy expenditure, or object memory recognition (Bell and Fadool, 2017). Hence, a possible mechanism of how high-fat diet perturbs insulin modulation of $\mathrm{M} / \mathrm{T}$ cells has been extensively studied by the laboratory of D. Fadool. They investigated the role of Kv1.3, a voltage-dependent, insulin-regulated potassium channel predominantly expressed in M/T cells and a main contributor to the total potassium current in these neurons (Fadool et al., 2000). As expected, the deletion of Kv1.3 has metabolic impacts. Mice double mutant for Kv1.3 show improved insulin sensitivity and an elevated energy expenditure. When challenged with a moderately high-fat diet of $32 \%$ fat for 26 weeks, $\mathrm{Kv} 1.3^{-/-}$mice fail to gain weight compared to their wild-type counterparts. Interestingly, removal of the MOB reverses their DIO resistance (Tucker et al., 2012b). These metabolic effects are accompanied by changes in the olfactory capacities as Kv1.3.- mice are "Super-smeller", they have improved olfactory performances (Fadool et al., 2004). Interestingly, a polymorphism in the human Kv1.3 gene that functionally elicits a gain in function has been associated with impaired glucose tolerance, lower insulin sensitivity, and impaired olfactory ability in male homozygous carriers (Tschritter et al., 2006).

\subsubsection{Ghrelin}

GHSR-1a type of ghrelin receptor is expressed in the different layers of the MOB and in the PCx. In lean rats, intracerebro-ventricular injection of ghrelin increases odor detection as tested in a conditioned odor aversion test (Tong et al., 2011). Ghrelin has also been related to sniffing as intra cerebroventricular injections of the compound enhanced exploratory sniffing in both rodents and humans (Tong et al., 2011). Then ghrelin could act to increase olfactory sensibility and performance before a meal. Ghrelin level is decreased in obese individuals (Tschöp et al., 2001) and HFD in mice has also been shown to trigger central ghrelin resistance by reducing both receptors' expression in the hypothalamus and AgRP neuronal responsiveness to ghrelin (Briggs et al., 2010; Naznin et al., 2015). Since ghrelin level is negatively correlated to BMI it is also negatively correlated to smell capability (Fernández-Aranda et al., 2016). Even though the independence of these two factors cannot be established, we can hypothesize that ghrelin resistance in HFD mice would reduce the impact of the metabolic status (fasted/fed) on olfactory perception and decrease its sensitivity. 


\subsubsection{Leptin}

Leptin-dependent obesity has only been observed in rare cases of obesity in humans (O'Rahilly, 1998). Nevertheless, obesity has typically been associated with leptin resistance, i.e. the inability of exogenous or endogenous circulating leptin to initiate metabolic outcomes, such as anorexigenic effects in obese individuals. Yet, the role of leptin in obesity especially in humans is still unclear (Myers et al., 2010).

Early studies have used animal models of leptin signaling dysfunctions to test odor perception. The ob/ob mice strain results from a spontaneous autosomal recessive mutation of the ob gene that produces leptin (Zhang et al., 1994). Very quickly during their growth these mice become overweight and develop metabolic syndromes characteristic of obesity: hyperphagia, transient hyperglycaemia and elevated plasma insulin concentration associated with an increase in the number and size of islet beta cells (Coleman, 1982). Obesity in ob / ob mice and the associated phenotypical alterations can be restored with exogenous administration of leptin. An analog model in rats is the Zucker strain, a genetic model of obesity driven by a mutation of the leptin receptor. The mutation causes an increase of food intake, a decrease of energy expenditure, hyperglycemia and insulin resistance (Yamashita et al., 1997). Contrarily ob/ob mice, the production of leptin is maintained but its affinity for the receptor is decreased.

Obesity caused by leptin signaling deficiency is associated with an increased olfactory detection threshold as seen for a buried food test in ob/ob mice (Getchell et al., 2006) as well as in Ob Zucker leptin-receptor-deficient rat (fa/fa) in a conditioned odor aversion protocol (Aimé et al., 2014). The Zucker fa/fa rats also exhibited greater food-seeking behavior when exposed to both novel and familiar olfactory cues (Thanos et al., 2008). In DIO rats, no difference in leptin receptors either in the mucosa or in the MOB was found (Lacroix et al., 2015). In addition, ob/ob mice performed better than wild-type (WT) mice in the early stage of an odor discrimination task, and brain rhythms associated with odorant processing, which mark the functional dialogue between the MOB and the PCx, were largely modified (Chelminski et al., 2017). This suggests a broader role for leptin that would modulate neuronal activity, functional connectivity and memory between brain structures within the olfactory system.

\subsection{Alteration of the olfactory structures: from the olfactory mucosa to associative brain regions}

In obesity, a chronic caloric excess will lead to non-subcutaneous ectopic fat mass accumulation. An excess of adipose tissue favors inflammatory cascades associated with the secretion of pro-inflammatory adipokines. This condition is associated with impaired insulin signaling triglyceride storage and basal lipolysis and an increase in the circulating fatty acids. When present in excess in the circulation, fatty acids become lipotoxic and promote dyslipidaemia, while fat deposition in the muscle promotes insulin resistance and fat deposition in the pancreas promotes $\beta$-cell dysfunction and insulin resistance (O'Brien et al., 2017). This type of inflammation can have dramatic consequences in the brain. Since we showed in this review that olfactory function is blunted in obese patients (with or without T2D, (Campolo et al., 2021)), in non-obese diabetic patients (Zhang et al., 2019), and even, in animal models, in non-obese non-diabetic mice fed with low quantities of HF (Takase et al., 2016), we postulate that inflammatory mechanisms in the brain are the main and early pathological events that could impair the olfactory system in all these different metabolic contexts. Noteworthy, fast HFD-induced inflammation is sufficient to decrease insulin sensitivity in non-obese non-diabetic rats (Cruciani-Guglielmacci et al., 2005).

\subsubsection{The olfactory mucosa}

Enriched diet has highly deleterious consequences on brain structures and functions. This is well documented in the hypothalamus where (De Souza et al., 2005) noted abnormal concentration 
circulating inflammatory markers including proinflammatory cytokines, IL-1, TNF $\alpha$ and IL-6 after 16 weeks of high fat diet. Hypercaloric diet intake related inflammation triggers changes in astrocytes, microglia and tanycyte physiology as well as vascular hyperpermeability (García-Cáceres et al., 2019). Moreover, inflammation processes and astrogliosis appear to start after only a week of hypercaloric diet availability, well before fat accumulation and systemic inflammation (Thaler et al., 2012; Clyburn and Browning, 2019).

In the olfactory system, highly deleterious inflammation has been documented as early as in the OM in mice fed with enriched food upon weaning and for 24 weeks. Similar effects on the mucosa are obtained using a high-fat diet (HF; 60\%) or moderately high-fat diet (MHF;32\%). Both conditions show an increase of microglial marker Iba-1 and a decrease in the number of ORNs in the OM due to apoptosis (Thiebaud et al., 2014; Fardone et al., 2019). The consequence of the reduced number of ORN is a decreased number of axonal projections to the glomerulus. Accordingly, apoptosis level is also increased in the OM of obesity-prone Sprague-Dawley rats fed with a HFHSD compared to obese-resistant rats fed with normal chow (Lacroix et al., 2015). This effect is accompanied by a decreased expression of insulin receptors, glucocorticoid receptors GLUT3 and GLUT4 and MCT1 type of monocarboxylate receptor with no difference in leptin receptors (Lacroix et al., 2015).

The extracellular electrical activity of olfactory receptors in the mucosa can be measured by electroolfactogram recordings. HFD exposure causes a decrease in the amplitude of the electro-olfactogram in response to odorants (Thiebaud et al., 2014), showing an alteration of signal transduction and suggesting poorer signal transmission to the MOB. In addition, four weeks of enriched fructose diet triggered diabetes in mice which exhibited a decline in olfactory behavior correlated to decreased electrophysiological responses of olfactory neurons recorded as a population and individually (Rivière et al., 2016).

\subsubsection{The main olfactory bulb}

At the level of the MOB, DIO has a clear structural impact. In transgenic mice carrying a GFP tag on the M72 odorant receptor, (Fardone et al., 2019) have described that in the medial but not the lateral glomerulus targeted by the M72 receptors, the number of juxta-glomerular cells is decreased in mild or HFD compared to control mice. The excitability of those cells is also impaired. Under olfactory activation, juxta-glomerular cells surrounding the lateral glomerulus exhibited a loss of activity that was stronger for HFD than for mild FD, whereas juxta-glomerular cells surrounding the medial glomerulus were equally impaired for both diets (Fardone et al., 2019). No effect in MOB neurogenesis was reported after 8 months of HFD (Lietzau et al., 2020), on the other hand, a reduction of neurogenesis was reported in the T2D model of Goto-Kakizaki rats (Lietzau et al., 2018). Furthermore, (Soleimanzad et al., 2019) examined resting state and odor-evoked hemodynamic profiles in the MOB of 3 months and 8 months HFD-fed mice by laser speckle contrast imaging. They observed that the relative changes in cerebral blood flow during olfactory stimulation were impaired in HFD compared to lean mice. This impairment was independent of blood vessel density a parameter not altered in HFD mice, but could rather be due to the impact of insulin resistance on neurovascular coupling.

In humans, a reduction in the MOB volume has previously been observed in pathologies presenting olfactory dysfunction, such as Parkinson's disease, Alzheimer's disease, schizophrenia, and depression (Turetsky et al., 2000; Thomann et al., 2009; Negoias et al., 2010). As observed in animals, an alteration of peripheral olfactory function can cause a reduction of the MOB volume associated with an alteration of olfactory performances (Gudziol et al., 2009). Thus, using MRI volumetric measurements in humans, studies have found a correlation between MOB volume and olfactory functions including odor threshold, odor discrimination, and odor identification (Rombaux et al., 2006; Buschhüter et al., 2008; Mazal et al., 2016). A recent study conducted by (Poessel et al., 2020a) showed that obesity and increasing BMI 
were associated with reduced MOB volume. Accordingly, the size of the MOB was negatively correlated with several metabolic indexes, i.e. HOMA-IR, levels of plasma leptin and body fat percentage.

\subsubsection{The piriform cortex}

Very few studies have examined neuroplasticity associated with metabolic diseases in the PCx. No effect on the volume of the $\mathrm{PCx}$ nor on the neuronal activation of piriform neurons assessed using c-fos were reported after 8 months of HFD (Lietzau et al., 2020). However, in T2D Goto-Kakizaki rats, (Lietzau et al., 2018) observed a decrease in parvalbumin expression and impairment of neuroblast differentiation in the PCx. In addition, the number of GABAergic $\mathrm{CB}+$ interneurons in the $\mathrm{PCx}$ dramatically decreased $(\sim 50 \%)$ in middle-aged T2D rats versus age-matched Wistar rats as a consequence of Calbindin-D28k down-regulation (Lietzau et al., 2016). Cellular stress characterized by increased JNK phosphorylation was also enhanced in T2D rats. Interestingly, both effects are counteracted by chronic treatment with the GLP-1 receptor agonist exendin-4 (Lietzau et al., 2016).

Besides, the expression of monocarboxylate transporters (MCTs) MCT1 and MCT2 was increased in the neurons of PCx of HFD-fed mice (Pierre et al., 2007). In HFD mice cortical neurons presented a high expression of both MCT1 and 2 whereas in normal conditions, neurons express mainly MCT2 and only low levels of MCT1. This increase was also observed in ob/ob mice fed with chow diet, ruling out a direct effect of nutrients. MCTs are membrane transporters that carry lactate, pyruvate and ketone bodies allowing the import and use of alternative energy substrates in conditions of metabolic challenges. The authors suggest that overexpression of MCTs in neurons could be a response obesityrelated brain insulin resistance and its impact on the utilization of energy substrates by brain cells. This is consistent with the action of insulin and glucose on neuronal activity in the PCx (Al Koborssy et al., 2019).

\subsection{Beyond the olfactory system: involvement of broader networks encompassing food intake regulation and reward}

\subsubsection{Alteration of the mesocorticolimbic system could impact food odor perception and attraction}

Numerous evidence point to a clear link between pathways governing hedonic control of food intake and overconsumption of palatable food in the context of metabolic syndrome and obesity. Maladaptive modifications within the mesocorticolimbic system could lead to olfactory impairment and alter the hedonic value of food odor cues.

In both hungry and satiated lean individuals, food odors presentation leads to higher activation of the anterior cingulate cortex, the insula and the putamen (ventral striatum) than the presentation of non-food odors. In addition, in hungry individuals both food and non-food odor stimulation activates the ventral tegmental area (Sorokowska et al., 2017). The frontostriatal loop, the connections between the striatum and the prefrontal cortex is dependent on dopamine release. This network subserves adaptive behavior hence alteration in the mesocorticolimbic system in the context of obesity is likely to change the perception of odorants. This pathway is known to be differentially activated in response to food-cue between obese and normal weighted individuals (Rothemund et al., 2007; Bragulat et al., 2010). More recently, a study by (Han et al., 2021) showed that despite their lower olfactory performances, obese individuals had enhanced activation of reward regions toward an odor of high energy content food (chocolate) compared to the odor of a low calories food (cucumber). More broadly, changes in general attentional processes in obesity could change the orientation of individuals toward food odor. Indeed, overweight and obese individuals present an enhanced reactivity to food cues (Hendrikse et al., 2015). 
In the context of an olfactory priming paradigm, evoked potentials measured when subjects perceived visual food cues primed by food odors were different between groups with different BMIs (Zsoldos et al., 2021).

In rodents, studies have shown that the OT could play a determining role in tagging the hedonic value of an odor (Millman and Murthy, 2020). This structure receives direct projections from the MOB and also from the ventral striatum, thus it belongs both to the olfactory cortex and the reward circuits. It receives projections from dopaminergic neurons in the ventral tegmental area which would be involved in the formation of olfactory preferences (Zhang et al., 2017). Likewise, increased activity of projections from the MOB towards the OT (Midroit et al., 2021) or from the Ventral Tegmental Area to the OT during odor exposure increases the attractiveness of odors (Zhang et al., 2017). Whereas it was not clearly established early on, the MOB receives direct projections from the reward system. Even though the tubercle does not project back to the $\mathrm{MOB}$, there is some evidence for direct projections from the substantia nigra (Höglinger et al., 2015) and from Tyrosine Hydroxylase positive neurons of the Ventral Tegmental Area and the ventral pallidum (Schneider et al., 2020) to the MOB.

To summarize, cerebral patterns elicited by food cues, and neural processing of hedonic olfactory information may be different in obese subjects. This difference could lead to a different level of awakening, including attention and motivation, provoked by food odor in obese individuals.

\subsubsection{A potential retrograde impact of the hypothalamus on odor processing}

It was shown that M/T cells project to ARC (Russo et al., 2018) and that Para Ventricular Nucleus cells in the hypothalamus respond to electrical stimulation of MOB (Guevara-Aguilar et al., 1988). Even though there is no evidence for a direct projection back from the arcuate nucleus of the hypothalamus to the olfactory system, we know that both POMC and AgRP neurons project onto orexin neurons located in the lateral hypothalamus, and interestingly there are direct projections of these orexin neurons to the MOB (Peyron et al., 1998; Gascuel et al., 2012). Besides, a recent work revealed the key role of the AgRP to paraventricular hypothalamus projections for hunger dependent food attraction by comparison with pheromone attraction (Horio and Liberles, 2021). The authors pointed the role of one of the principal neurotransmitters released by AgRP neurons, Neuropeptide Y (NPY) and its receptor NPY5R. Indeed, fasted NPY-KO mice failed to be more attracted by food odor than by pheromone contrarily to control mice, an effect reversed by injections of NPY5R agonists in the paraventricular hypothalamus. On the contrary, injection of NPY5R antagonists into the paraventricular thalamus blocked food-odor attraction in fasted mice. Then, the hypothalamo-olfactory network would control alliesthesia for food cues, i.e. the modulation in the reward value of a stimulus according to the internal state and the potential to move the body's physiological state towards homeostasis. An alteration of this mechanism in obesity could be responsible for the modification of olfactory processing of food vs. nonfood odors in obesity.

\subsubsection{Decrease in olfactory acuity by functional changes in the trigeminal activation}

Obesity also results in functional changes to the trigeminal system. In obese HFD mice, photophobic behavior is induced by a lower dose of capsaicin intradermally injected in the face and functional TRPV1 expression is altered in trigeminal ganglion neurons (Rossi et al., 2016). Data are lacking regarding the activity of neurons connecting the trigeminal ganglion and the olfactory system in obese mice. However, in a study conducted in teenagers (10-16 years old) the impact of obesity on olfaction was shown to be stronger for odorants that stimulate both olfactory and trigeminal nerves than for odorants stimulating only the olfactory nerve (Obrebowski et al., 2000). 
As mentioned previously, the trigeminal nerve activation participates to olfactory processing since the majority of odorants also activate the TRPV family of cation channels expressed at the endings of trigeminal fibers. Thus, alteration of the trigeminal system could cause olfactory changes observed in obese patients and contribute to a perceptual and cognitive difference in obesity as compared to nonobese individuals.

\section{Pharmacological treatments}

Type 1 endocannabinoid receptor (CB1R) is expressed in the CNS and is notably implicated in the regulation of food intake. It was targeted by rimonabant, a CB1R inverse agonist investigated as a treatment for obesity and the metabolic syndrome, which triggered deleterious side effects on mood in some obese patients and was withdrawn in 2008, two years after its approval. The role of CB1R in food intake inhibition via the MOB has been studied: CB1R are implicated in the regulation of glutamatergic feedback projections to the MOB, more specifically those originating from the anterior olfactory cortex (Soria-Gómez et al., 2014b). These projections play a determining role in the activity of granule cells, the main GABAergic interneurons of the MOB. Hunger induces the activation of the CB1R in the olfactory circuits, and pharmacological activation of the CB1R, specifically at the level of the MOB, is sufficient to increase food intake, with an improvement in olfactory performance (Soria-Gómez et al., 2014a). CB1R are also highly expressed in the PCx and are required for the expression of appetitive olfactory memory (Terral et al., 2019). Moreover, the endocannabinoid system is involved in the regulation of food intake in connection with the mechanisms of reward (Lau et al., 2017). The deletion of CB1 in dorsal telencephalic excitatory neurons regulating hedonic feeding behavior protects against pathological effects of DIO (Ruiz de Azua et al., 2021). However, the rescue of CB1 expression in glutamatergic neurons locally in the olfactory cortex partly restored DIO._The tone of the endocannabinoid system is enhanced in obesity and CB1 inhibitors are a strategy for obesity management (Behl et al., 2021). Consistently, elevated fasting plasma concentrations of the circulating endocannabinoid 2-arachidonoylglycerol (2-AG) in obesity are linked to a lower TDI score (Pastor et al., 2016). The modified activity of the endocannabinoid system and its connection with the mechanisms of sensory perception and reward could explain why obese individuals have different sensibility toward food and non-food odorants, and between neutral and appealing odorant compared to lean counterparts. A promising pharmacological approach would be to use CB1R as a target for both olfactory (BhatiaDey and Heinbockel, 2020) and metabolic (Hirsch and Tam, 2019) problems but this strategy will need further clinical research in olfactory perception under cannabinoid therapeutics. Interestingly, a dual approach, combining a peripheral CB1R antagonist with a GLP-1R agonist was shown to potentiate the anti-obesity and anti-diabetic effects of GLP-1R agonist alone in DIO mice (Zizzari et al., 2021).

Recent research studying the fate of smell in T2D has shown that Glucagon Like Peptide-1 (GLP-1) was an interesting hormonal target linking olfaction and T2D: (Zhang et al., 2019) studied 35 obese and 35 non-obese people with T2D compared to 35 control subjects matched for age (35-70 years), sex, and education. Among the 35 obese subjects, 20 obese individuals with diabetes with inadequate glycemic control and metformin monotherapy received GLP-1 receptor agonist treatment (liraglutide and exenatide) for 3 months. Obese T2D subjects demonstrated lower score in the cognitive test (MiniMental State Examination, MMSE) and in the olfactory test (increase in olfactory threshold revealed by UPSIT) compared to non-obese participants with diabetes (these diabetic patients also present an impairment compared to control subjects). Interestingly, with 3-month GLP-1 receptor agonist treatment, obese subjects with diabetes exhibited improved cognitive and olfactory scores. This olfactory rescue by GLP-1 analogs can be explained by the expression of GLP-1R by M/T cells that are strongly excited by GLP-1 in in vitro mouse MOB slices (Thiebaud et al., 2016, 2019). In addition, chronic exendin-4 treatment reduced neuronal alterations observed in the PCx in the genetic model of 
T2D rats (Lietzau et al., 2016). In the same model, chronic treatment with the Dipeptidyl peptidase-4 inhibitor (DPP-4i) linagliptin did not improve odorant detection, nevertheless, it normalized T2Dinduced effects on neurogenesis in the MOB (Lietzau et al., 2018). Overall, GLP-1R expressed in the olfactory system is a good candidate for pharmacological treatment to rescue olfaction in the context of obesity and T2D.

Table 1. Mechanisms linking impaired smell to obesity and type 2 diabetes

\begin{tabular}{|l|l|l|l|}
\hline $\begin{array}{l}\text { Neurodegeneration } \\
\text { or alteration of } \\
\text { neuronal response } \\
\text { from inflammatory } \\
\text { processes }\end{array}$ & $\begin{array}{l}\text { Oardone et al., 2019; } \\
\text { Lacroix et al., 2015; } \\
\text { Rivière et al., 2016; } \\
\text { Thiebaud et al., 2014 }\end{array}$ & $\begin{array}{l}\text { Main Olfactory Bulb } \\
\text { 2020; Fardone et al., } \\
2019 ; \text { Poessel et al., } \\
2020 \mathrm{a}\end{array}$ & \multicolumn{1}{c|}{ Olfactory Cortex } \\
\hline Insulin resistance & & $\begin{array}{l}\text { Fadool et al., 2004; } \\
\text { Aimé et al., 2012; } \\
\text { Tucker et al., 2012a; } \\
\text { Lacroix et al., 2015; } \\
\text { Min and Min, 2018; } \\
\text { Poessel et al., 2020b }\end{array}$ & $\begin{array}{l}\text { Al Koborssy et al., } \\
2019\end{array}$ \\
\hline Leptin resistance & & $\begin{array}{l}\text { Getchell et al., 2006; } \\
\text { Chelminski et al., 2017 }\end{array}$ & \\
\hline $\begin{array}{l}\text { Vascular } \\
\text { dysfunction }\end{array}$ & & $\begin{array}{l}\text { Soleimanzad et al., } \\
\text { 2019 }\end{array}$ & \\
\hline Glucotoxicity & & Zaghloul et al., 2018 & $\begin{array}{l}\text { Al Koborssy et al., } \\
2019\end{array}$ \\
\hline
\end{tabular}

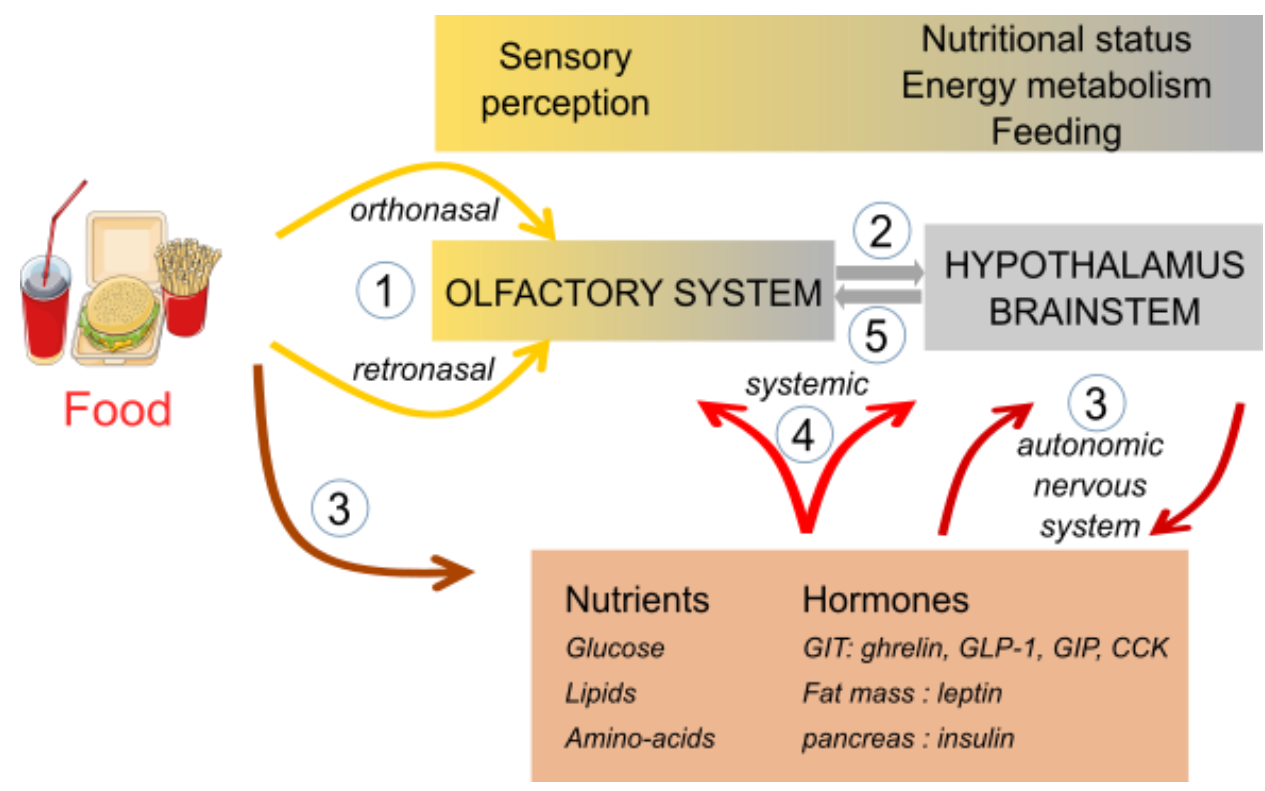

\section{Figure 4}

Summary and chronology of the events related to food intake which directly or indirectly impact the olfactory system, and which may be altered in condition of T2D or obesity. GIT = gastro-intestinal tract; GLP-1 = Glucagon-like peptide-1; GIP = Gastric inhibitory polypeptide; $C C K=$ Cholecystokinin. 


\section{Perspectives}

Data reviewed in both humans and animal models converge to show that obesity and T2D are associated with an alteration of olfactory performances. Confounding factors such as age and sex have to be taken into account when considering olfactory testing. It appears that there might also be differences in alteration between the type of odorant and their hedonic content. Indeed, we noticed that obese and lean individuals have dissociated performances toward neutral versus food related odorants.

Processing odors and particularly food related odor involves a large set of brain structures, hence finding the origin of olfactory defect in obesity and T2D is not trivial. As the metabolic causes and consequences of metabolic disorders, olfactory impairment are likely to be multifactorial (table 1 and figure 4). Since improvement in metabolic health is correlated with better olfactory performances, treatment of the symptoms of obesity are likely to be associated with better olfactory abilities. For instance, physical exercise has been shown to reduce the risk of olfactory impairment in older adults (Schubert et al., 2013). However, we lack controlled studies for the evaluation of such parameters in the context of obesity or T2D probably because they require longitudinal studies on the long term.

It is unlikely that olfactory changes could be the cause of obesity, nevertheless one can wonder to what extent it could accentuate the disease. A difference in olfactory perception between obese and normalweighted individuals has been suggested to cause differences in food choice and energy consumption (Drewnowski et al., 1995, 1997). We have described how the MOB has many characteristics of a metabolic sensor and olfactory activity would also participate in the modulation of peripheral energy metabolism in mice (Riera et al., 2017). Further probing of the olfactory function in longitudinal studies starting in overweight subjects would be needed to describe the possible participation of smell deficiency in the causal mechanisms leading to dysregulated food intake and obesity. More generally it is acknowledged that olfactory deficits dramatically impair general quality of life, mainly because of the consequences on food intake (enjoyment of food, increase/decrease appetite) (Croy et al., 2014). One treatment option available for post-viral olfactory dysfunction is daily olfactory training, that shows significant olfactory improvement (Denis et al., 2021). We suggest that the same training could be used in obese patients with the aim of improving olfactory and feeding dysregulations.

In the light of recent findings, we propose that probing olfactory perception can be used as a biomarker in clinics to check the fate of energy metabolism (Midorikawa et al., 2021). First, it was shown that among T2D obese patients, those with olfactory problems have also the most severe cognitive dysfunction (Zhang et al., 2018). In that sense, Sanke et al. (2021) recently showed that olfactory impairment is a predictive clinical sign of dementia in elderlies with T2D. Hence, olfactory defects could be used as an early biomarker to detect incoming cognitive problems in the context of metabolic diseases. In addition, a promising avenue is the use of olfactory monitoring among the factors assessing metabolic and weight recovery after bariatric surgery (Guyot et al., 2021).

To conclude, based on information presented in this review, we advocate that both olfactory assessment and reeducation could be more generally used in the context of metabolic diseases and may bring a significant added value to multidisciplinary team-based obesity treatment.

Acknowledgements: This work was supported by the UChicago - CNRS Collaboration Program 2020 (MF); Agence Nationale de la Recherche (ANR): ANR-16-CE14-0026 Fat4Brain (ChM), the Société Francophone du Diabète (ChM), IdEx Université de Paris, ANR-18-IDEX-0001 (ClM) and by recurrent funding from Université de Paris and CNRS (ChM, HG, ClM) 


\section{References}

Addison OR, Ryan AS (2018) Body Weight, Body Composition, and Aging. In: Encyclopedia of Endocrine Diseases, Academic Press., pp 4252.

Ahmed K, Penney N, Darzi A, Purkayastha S (2018) Taste Changes after Bariatric Surgery: a Systematic Review. OBES SURG 28:3321-3332.

Aimé $P$, Hegoburu C, Jaillard T, Degletagne C, Garcia S, Messaoudi B, Thevenet $M$, Lorsignol A, Duchamp C, Mouly A-M, Julliard AK (2012) A physiological increase of insulin in the olfactory bulb decreases detection of a learned aversive odor and abolishes food odor-induced sniffing behavior in rats. PLOS ONE 7:e51227.

Aimé P, Palouzier-Paulignan B, Salem R, Al Koborssy D, Garcia S, Duchamp C, Romestaing C, Julliard AK (2014) Modulation of olfactory sensitivity and glucose-sensing by the feeding state in obese Zucker rats. Front Behav Neurosci 8.

Al Koborssy D, Palouzier-Paulignan B, Canova V, Thevenet M, Fadool DA, Julliard AK (2019) Modulation of olfactory-driven behavior by metabolic signals: role of the piriform cortex. Brain Struct Funct 224:315-336.

Al Koborssy D, Palouzier-Paulignan B, Salem R, Thevenet M, Romestaing C, Julliard AK (2014) Cellular and molecular cues of glucose sensing in the rat olfactory bulb. Front Neurosci 8.

Angrisani L, Santonicola A, lovino P, Formisano G, Buchwald H, Scopinaro N (2015) Bariatric Surgery Worldwide 2013. Obes Surg 25:1822-1832.

Aschenbrenner K, Scholze N, Joraschky P, Hummel T (2008) Gustatory and olfactory sensitivity in patients with anorexia and bulimia in the course of treatment. Journal of Psychiatric Research 43:129-137.

Badonnel K, Lacroix M-C, Durieux D, Monnerie R, Caillol M, Baly C (2014) Rat strains with different metabolic statuses differ in food olfactory-driven behavior. Behav Brain Res 270:228-239.

Banks WA, Kastin AJ, Pan W (1999) Uptake and degradation of blood-borne insulin by the olfactory bulb. Peptides 20:373-378.

Baskin DG, Schwartz MW, Sipols AJ, D’Alessio DA, Goldstein BJ, White MF (1994) Insulin receptor substrate-1 (IRS-1) expression in rat brain. Endocrinology 134:1952-1955.

Behl T, Chadha S, Sachdeva M, Sehgal A, Kumar A, Dhruv, Venkatachalam T, Hafeez A, Aleya L, Arora $S$, Batiha GE-S, Nijhawan P, Bungau S (2021) Understanding the possible role of endocannabinoid system in obesity. Prostaglandins \& Other Lipid Mediators 152:106520.

Bell GA, Fadool DA (2017) Awake, long-term intranasal insulin treatment does not affect object memory, odor discrimination, or reversal learning in mice. Physiol Behav 174:104-113.

Berthoud H-R (2004) Mind versus metabolism in the control of food intake and energy balance. Physiology \& Behavior 81:781-793.

Berthoud H-R, Morrison C (2008) The Brain, Appetite, and Obesity. Annual Review of Psychology 59:55-92. 
Besser G, Erlacher B, Aydinkoc-Tuzcu K, Liu DT, Pablik E, Niebauer V, Koenighofer M, Renner B, Mueller CA (2020) Body-Mass-Index Associated Differences in Ortho- and Retronasal Olfactory Function and the Individual Significance of Olfaction in Health and Disease. Journal of Clinical Medicine 9:366.

Betley JN, Cao ZF, Ritola KD, Sternson SM (2013) Parallel, redundant circuit organization for homeostatic control of feeding behavior. Cell 155:1337-1350.

Bhatia-Dey N, Heinbockel T (2020) Endocannabinoid-Mediated Neuromodulation in the Olfactory Bulb: Functional and Therapeutic Significance. International Journal of Molecular Sciences 21:2850.

Boesveldt S, de Graaf K (2017) The Differential Role of Smell and Taste For Eating Behavior. Perception 46:307-319.

Boesveldt S, Postma EM, Boak D, Welge-Luessen A, Schöpf V, Mainland JD, Martens J, Ngai J, Duffy VB (2017) Anosmia-A Clinical Review. Chem Senses 42:513-523.

Bojanowski V, Hummel T (2012) Retronasal perception of odors. Physiology \& Behavior 107:484-487.

Bonatti M (1950) [Diabetes and taste]. Arcisp S Anna Ferrara 3:245-253.

Brady S, Lalli P, Midha N, Chan A, Garven A, Chan C, Toth C (2013) Presence of Neuropathic Pain May Explain Poor Performances on Olfactory Testing in Diabetes Mellitus Patients. Chemical Senses 38:497-507.

Bragulat V, Dzemidzic M, Bruno C, Cox CA, Talavage T, Considine RV, Kareken DA (2010) Food-Related Odor Probes of Brain Reward Circuits During Hunger: A Pilot fMRI Study. Obesity 18:15661571.

Brämerson A, Johansson L, Ek L, Nordin S, Bende M (2004) Prevalence of Olfactory Dysfunction: The Skövde Population-Based Study. The Laryngoscope 114:733-737.

Brand G (2006) Olfactory/trigeminal interactions in nasal chemoreception. Neuroscience \& Biobehavioral Reviews 30:908-917.

Braun J-J, Renaud M, Moliere S, Noblet V, Kremer S, Dolfus H, Riehm S (2019) Diagnostic Findings in 60 Cases of Isolated and Syndromic Congenital Olfactory Dysfunction. Int Arch Transl Med 5:008.

Briggs DI, Enriori PJ, Lemus MB, Cowley MA, Andrews ZB (2010) Diet-induced obesity causes ghrelin resistance in arcuate NPY/AgRP neurons. Endocrinology 151:4745-4755.

Buschhüter D, Smitka M, Puschmann S, Gerber JC, Witt M, Abolmaali ND, Hummel T (2008) Correlation between olfactory bulb volume and olfactory function. Neuroimage 42:498-502.

Cabanac M, Duclaux R (1973) [Olfactory-gustatory alliesthesia and food intake in humans]. J Physiol (Paris) 66:113-135.

Cain WS, Reid F, Stevens JC (1990) Missing Ingredients. Journal of Nutrition For the Elderly 9:3-15.

Campolo J, Corradi E, Rizzardi A, Parolini M, Dellanoce C, Di Guglielmo ML, Tarlarini P, Cattaneo M, Trivella MG, De Maria R (2021) Correlates of olfactory impairment in middle-aged non- 
diabetic Caucasian subjects with stage I-II obesity. Eur Arch Otorhinolaryngol 278:20472054.

Catamo E, Tornese G, Concas MP, Gasparini P, Robino A (2021) Differences in taste and smell perception between type 2 diabetes mellitus patients and healthy controls. Nutrition, Metabolism and Cardiovascular Diseases 31:193-200.

Chan JYK, García-Esquinas E, Ko OH, Tong MCF, Lin SY (2018) The Association Between Diabetes and Olfactory Function in Adults. Chemical Senses 43:59-64.

Chatterjee S, Khunti K, Davies MJ (2017) Type 2 diabetes. The Lancet 389:2239-2251.

Chelminski Y, Magnan C, Luquet SH, Everard A, Meunier N, Gurden H, Martin C (2017) Odor-Induced Neuronal Rhythms in the Olfactory Bulb Are Profoundly Modified in ob/ob Obese Mice. Front Physiol 8.

Chen Y, Lin Y-C, Kuo T-W, Knight ZA (2015) Sensory Detection of Food Rapidly Modulates Arcuate Feeding Circuits. Cell 160:829-841.

Clyburn C, Browning KN (2019) Role of astroglia in diet-induced central neuroplasticity. Journal of Neurophysiology 121:1195-1206.

Coleman DL (1982) Diabetes-obesity syndromes in mice. Diabetes 31:1-6.

Coluzzi I, Raparelli L, Guarnacci L, Paone E, Del Genio G, le Roux CW, Silecchia G (2016) Food Intake and Changes in Eating Behavior After Laparoscopic Sleeve Gastrectomy. OBES SURG 26:2059-2067.

Croy I, Nordin S, Hummel T (2014) Olfactory disorders and quality of life--an updated review. Chem Senses 39:185-194.

Cruciani-Guglielmacci C, Vincent-Lamon M, Rouch C, Orosco M, Ktorza A, Magnan C (2005) Early changes in insulin secretion and action induced by high-fat diet are related to a decreased sympathetic tone. American Journal of Physiology-Endocrinology and Metabolism 288:E148E154.

Czernichow S, Renuy A, Rives-Lange C, Carette C, Airagnes G, Wiernik E, Ozguler A, Kab S, Goldberg $M$, Zins M, Matta J (2021) Evolution of the prevalence of obesity in the adult population in France, 2013-2016: the Constances study. Sci Rep 11:14152.

De Souza CT, Araujo EP, Bordin S, Ashimine R, Zollner RL, Boschero AC, Saad MJ, Velloso LA (2005) Consumption of a fat-rich diet activates a proinflammatory response and induces insulin resistance in the hypothalamus. Endocrinology 146:4192-4199.

Denis F, Septans A-L, Periers L, Maillard J-M, Legoff F, Gurden H, Moriniere S (2021) Olfactory Training and Visual Stimulation Assisted by a Web Application for Patients With Persistent Olfactory Dysfunction After SARS-CoV-2 Infection: Observational Study. J Med Internet Res 23:e29583.

Doty RL, Kamath V (2014) The influences of age on olfaction: a review. Front Psychol 5 Available at: https://www.frontiersin.org/articles/10.3389/fpsyg.2014.00020/full. 
Doty RL, Shaman P, Dann M (1984) Development of the university of pennsylvania smell identification test: A standardized microencapsulated test of olfactory function. Physiology \& Behavior 32:489-502.

Drewnowski A, Krahn DD, Demitrack MA, Nairn K, Gosnell BA (1995) Naloxone, an opiate blocker, reduces the consumption of sweet high-fat foods in obese and lean female binge eaters. The American Journal of Clinical Nutrition 61:1206-1212.

Drewnowski A, Renderson SA, Driscoll A, Rolls BJ (1997) The Dietary Variety Score: Assessing Diet Quality in Healthy Young and Older Adults. Journal of the American Dietetic Association 97:266-271.

Duclaux R, Feisthauer J, Cabanac M (1973) [Effects of a meal on the pleasantness of food and nonfood odors in man] Effets du repas sur l'agrément d'odeurs alimentaires et nonalimentaires chez l'homme. Physiology \& Behavior 10:1029-1033.

Eckel RH, Kahn SE, Ferrannini E, Goldfine AB, Nathan DM, Schwartz MW, Smith RJ, Smith SR (2011) Obesity and Type 2 Diabetes: What Can Be Unified and What Needs to Be Individualized? The Journal of Clinical Endocrinology \& Metabolism 96:1654-1663.

Enck P, Rieber N, Sauer H, Klosterhalfen S, Mack I, Zipfel S, Teufel M (2014) Almost Nothing - Not Even Bariatric Surgery for Obesity - Changes Olfactory Sensitivity. IBIMA Publishing 2014:Article ID 491890.

Fadool DA, Tucker K, Pedarzani P (2011) Mitral cells of the olfactory bulb perform metabolic sensing and are disrupted by obesity at the level of the Kv1.3 ion channel. PLoS ONE 6:e24921.

Fadool DA, Tucker K, Perkins R, Fasciani G, Thompson RN, Parsons AD, Overton JM, Koni PA, Flavell RA, Kaczmarek LK (2004) Kv1.3 Channel Gene-Targeted Deletion Produces "Super-Smeller Mice" with Altered Glomeruli, Interacting Scaffolding Proteins, and Biophysics. Neuron 41:389-404.

Fadool DA, Tucker K, Phillips JJ, Simmen JA (2000) Brain insulin receptor causes activity-dependent current suppression in the olfactory bulb through multiple phosphorylation of Kv1.3. J Neurophysiol 83:2332-2348.

Fardone E, Celen AB, Schreiter NA, Thiebaud N, Cooper ML, Fadool DA (2019) Loss of odor-induced cFos expression of juxtaglomerular activity following maintenance of mice on fatty diets. J Bioenerg Biomembr 51:3-13.

Fernández-Aranda F et al. (2016) Smell-taste dysfunctions in extreme weight/eating conditions: analysis of hormonal and psychological interactions. Endocrine 51:256-267.

Fernandez-Garcia JC, Alcaide J, Santiago-Fernandez C, Roca-Rodriguez MM, Aguera Z, Baños R, Botella C, de la Torre R, Fernandez-Real JM, Fruhbeck G, Gomez-Ambrosi J, Jimenez-Murcia S, Menchon JM, Casanueva FF, Fernandez-Aranda F, Tinahones FJ, Garrido-Sanchez L (2017) An increase in visceral fat is associated with a decrease in the taste and olfactory capacity. PLoS One 12:e0171204.

Ferriday D, Brunstrom JM (2008) How does food-cue exposure lead to larger meal sizes? British Journal of Nutrition 100:1325-1332. 
Ferriday D, Brunstrom JM (2011) 'I just can't help myself': effects of food-cue exposure in overweight and lean individuals. Int J Obes 35:142-149.

Firestein S (2001) How the olfactory system makes sense of scents. Nature 413:211-218.

Floch J-PL, Lièvre GL, Labroue M, Paul M, Peynegre R, Perlemuter L (1993) Smell Dysfunction and Related Factors in Diabetic Patients. Diabetes Care 16:934-937.

Fournel A, lannilli E, Ferdenzi C, Werner A, Hummel T, Bensafi M (2020) A methodological investigation of a flexible surface MRI coil to obtain functional signals from the human olfactory bulb. Journal of Neuroscience Methods 335:108624.

García-Cáceres C, Balland E, Prevot V, Luquet S, Woods SC, Koch M, Horvath TL, Yi C-X, Chowen JA, Verkhratsky A, Araque A, Bechmann I, Tschöp MH (2019) Role of astrocytes, microglia, and tanycytes in brain control of systemic metabolism. Nature Neuroscience 22:7-14.

Garrison JL, Knight ZA (2017) Linking smell to metabolism and aging. Science 358:718-719.

Gascón C, Santaolalla F, Martínez A, Sánchez Del Rey A (2013) Usefulness of the BAST-24 smell and taste test in the study of diabetic patients: a new approach to the determination of renal function. Acta Otolaryngol 133:400-404.

Gascuel J, Lemoine A, Rigault C, Datiche F, Benani A, Penicaud L, Lopez-Mascaraque L (2012) Hypothalamus-Olfactory System Crosstalk: Orexin A Immunostaining in Mice. Front Neuroanat 6.

Getchell TV, Kwong K, Saunders CP, Stromberg AJ, Getchell ML (2006) Leptin regulates olfactorymediated behavior in ob/ob mice. Physiol Behav 87:848-856.

Ghibaudi L, Cook J, Farley C, Heek M van, Hwa JJ (2002) Fat Intake Affects Adiposity, Comorbidity Factors, and Energy Metabolism of Sprague-Dawley Rats. Obesity Research 10:956-963.

Goetzl FR, Abel MS, Ahokas AJ (1950) Occurence in Normal Individuals of Diurnal Variations in Olfactory Acuity. Journal of Applied Physiology 2:553-562.

Gouveri E, Katotomichelakis M, Gouveris H, Danielides V, Maltezos E, Papanas N (2014) Olfactory Dysfunction in Type 2 Diabetes Mellitus: An Additional Manifestation of Microvascular Disease? Angiology 65:869-876.

Graham L, Murty G, Bowrey DJ (2014) Taste, smell and appetite change after Roux-en-Y gastric bypass surgery. Obes Surg 24:1463-1468.

Gudziol V, Buschhüter D, Abolmaali N, Gerber J, Rombaux P, Hummel T (2009) Increasing olfactory bulb volume due to treatment of chronic rhinosinusitis-a longitudinal study. Brain 132:3096-3101.

Guevara-Aguilar R, Jimenez-Montufar LL, Garcia-Diaz DE, Wayner MJ, Armstrong DL (1988) Olfactory and visceral projections to the paraventricular nucleus. Brain Res Bull 20:799-801.

Guyot E, Dougkas A, Robert M, Nazare J-A, Iceta S, Disse E (2021) Food Preferences and Their Perceived Changes Before and After Bariatric Surgery: a Cross-sectional Study. OBES SURG 31:3075-3082. 
Hammer FJ (1951) The relation of odor, taste, and flicker-fusion thresholds to food intake. Journal of Comparative and Physiological Psychology 44:403-411.

Han P, Roitzsch C, Horstmann A, Pössel M, Hummel T (2021) Increased Brain Reward Responsivity to Food-Related Odors in Obesity. Obesity 29:1138-1145.

Hancı D, Altun H, Altun H, Batman B, Karip AB, Serin KR (2016) Laparoscopic Sleeve Gastrectomy Improves Olfaction Sensitivity in Morbidly Obese Patients. Obes Surg 26:558-562.

Hariri N, Thibault L (2010) High-fat diet-induced obesity in animal models. Nutrition Research Reviews 23:270-299.

Hawkins KA, Pearlson GD (2011) Age and Gender but Not Common Chronic Illnesses Predict Odor Identification in Older African Americans. The American Journal of Geriatric Psychiatry 19:777-782.

Hendrikse JJ, Cachia RL, Kothe EJ, McPhie S, Skouteris H, Hayden MJ (2015) Attentional biases for food cues in overweight and individuals with obesity: a systematic review of the literature. Obesity Reviews 16:424-432.

Herbert BM, Pollatos O (2014) Attenuated interoceptive sensitivity in overweight and obese individuals. Eating Behaviors 15:445-448.

Herman AM, Ortiz-Guzman J, Kochukov M, Herman I, Quast KB, Patel JM, Tepe B, Carlson JC, Ung K, Selever J, Tong $Q$, Arenkiel BR (2016) A cholinergic basal forebrain feeding circuit modulates appetite suppression. Nature 538:253-256.

Hill JM, Lesniak MA, Pert CB, Roth J (1986) Autoradiographic localization of insulin receptors in rat brain: prominence in olfactory and limbic areas. Neuroscience 17:1127-1138.

Hirsch S, Tam J (2019) Cannabis: From a Plant That Modulates Feeding Behaviors toward Developing Selective Inhibitors of the Peripheral Endocannabinoid System for the Treatment of Obesity and Metabolic Syndrome. Toxins 11:275.

Höglinger GU, Alvarez-Fischer D, Arias-Carrión O, Djufri M, Windolph A, Keber U, Borta A, Ries V, Schwarting RKW, Scheller D, Oertel WH (2015) A new dopaminergic nigro-olfactory projection. Acta Neuropathol 130:333-348.

Holinski F, Menenakos C, Haber G, Olze H, Ordemann J (2015) Olfactory and Gustatory Function After Bariatric Surgery. OBES SURG 25:2314-2320.

Horio N, Liberles SD (2021) Hunger enhances food-odour attraction through a neuropeptide $Y$ spotlight. Nature:1-5.

Hummel T, Sekinger B, Wolf SR, Pauli E, Kobal G (1997) 'Sniffin' Sticks': Olfactory Performance Assessed by the Combined Testing of Odor Identification, Odor Discrimination and Olfactory Threshold. Chemical Senses 22:39-52.

Iravani B, Arshamian A, Ohla K, Wilson DA, Lundström JN (2020) Non-invasive recording from the human olfactory bulb. Nature Communications 11:648.

Islam MA, Fagundo AB, Arcelus J, Agüera Z, Jiménez-Murcia S, Fernández-Real JM, Tinahones FJ, de la Torre R, Botella C, Frühbeck G, Casanueva FF, Menchón JM, Fernandez-Aranda F (2015) 
Olfaction in eating disorders and abnormal eating behavior: a systematic review. Front Psychol 6.

Jørgensen MB, Buch NH (1961) Studies on the Sense of Smell and Taste in Diabetics. Acta OtoLaryngologica 53:539-545.

Joseph T, Auger SD, Peress L, Rack D, Cuzick J, Giovannoni G, Lees A, Schrag AE, Noyce AJ (2019) Screening performance of abbreviated versions of the UPSIT smell test. J Neurol 266:18971906.

Julliard A-K, Al Koborssy D, Fadool DA, Palouzier-Paulignan B (2017) Nutrient Sensing: Another Chemosensitivity of the Olfactory System. Front Physiol 8.

Jurowich CF, Seyfried F, Miras AD, Bueter M, Deckelmann J, Fassnacht M, Germer C-T, Thalheimer A (2014) Does bariatric surgery change olfactory perception? Results of the early postoperative course. Int J Colorectal Dis 29:253-260.

Kim SJ, Windon MJ, Lin SY (2019) The association between diabetes and olfactory impairment in adults: A systematic review and meta-analysis. Laryngoscope Investig Otolaryngol 4:465-475.

Koelega HS (1994) Diurnal Variations in Olfactory Sensitivity and the Relationship to Food Intake. Percept Mot Skills 78:215-226.

Koliaki C, Liatis S, le Roux CW, Kokkinos A (2017) The role of bariatric surgery to treat diabetes: current challenges and perspectives. BMC Endocrine Disorders 17:50.

Kuczewski N, Fourcaud-Trocmé N, Savigner A, Thevenet M, Aimé P, Garcia S, Duchamp-Viret P, Palouzier-Paulignan B (2014) Insulin modulates network activity in olfactory bulb slices: impact on odour processing. J Physiol 592:2751-2769.

Kurian SM, Naressi RG, Manoel D, Barwich A-S, Malnic B, Saraiva LR (2021) Odor coding in the mammalian olfactory epithelium. Cell Tissue Res 383:445-456.

Lacroix M-C, Badonnel K, Meunier N, Tan F, Poupon CS-L, Durieux D, Monnerie R, Baly C, Congar P, Salesse R, Caillol M (2008) Expression of Insulin System in the Olfactory Epithelium: First Approaches to its Role and Regulation. Journal of Neuroendocrinology 20:1176-1190.

Lacroix M-C, Caillol M, Durieux D, Monnerie R, Grebert D, Pellerin L, Repond C, Tolle V, Zizzari P, Baly $C$ (2015) Long-Lasting Metabolic Imbalance Related to Obesity Alters Olfactory Tissue Homeostasis and Impairs Olfactory-Driven Behaviors. Chemical Senses 40:537-556.

Landis BN, Konnerth CG, Hummel T (2004) A Study on the Frequency of Olfactory Dysfunction. The Laryngoscope 114:1764-1769.

Lau BK, Cota D, Cristino L, Borgland SL (2017) Endocannabinoid modulation of homeostatic and nonhomeostatic feeding circuits. Neuropharmacology 124:38-51.

Le Magnen J (1956) Le rôle des stimulations olfacto-gustatives dans les mécanismes de régulation de la prise alimentaire. Annales de la nutrition et de l'alimentation 10:153-188.

Le Magnen J (2001) My scientific life: 40 years at the College de France. Neuroscience \& Biobehavioral Reviews 25:375-394. 
Lecoq J, Tiret P, Najac M, Shepherd GM, Greer CA, Charpak S (2009) Odor-Evoked Oxygen Consumption by Action Potential and Synaptic Transmission in the Olfactory Bulb. J Neurosci 29:1424-1433.

Lietzau G, Davidsson W, Östenson C-G, Chiazza F, Nathanson D, Pintana H, Skogsberg J, Klein T, Nyström T, Darsalia V, Patrone C (2018) Type 2 diabetes impairs odour detection, olfactory memory and olfactory neuroplasticity; effects partly reversed by the DPP-4 inhibitor Linagliptin. acta neuropathol commun 6:14.

Lietzau G, Nyström T, Östenson C-G, Darsalia V, Patrone C (2016) Type 2 diabetes-induced neuronal pathology in the piriform cortex of the rat is reversed by the GLP-1 receptor agonist exendin4. Oncotarget 7:5865-5876.

Lietzau G, Nyström T, Wang Z, Darsalia V, Patrone C (2020) Western Diet Accelerates the Impairment of Odor-Related Learning and Olfactory Memory in the Mouse. ACS Chem Neurosci 11:35903602.

Luquet S, Joly A, Denis R, Palmiter R, Magnan C (2010) Arcuate NPY/AgRP neurons and the control of energy balance. European Neuropsychopharmacology 20:S195-S196.

Mainland JD, Lundström JN, Reisert J, Lowe G (2014) From molecule to mind: an integrative perspective on odor intensity. Trends Neurosci 37:443-454.

Makaronidis JM, Neilson S, Cheung W-H, Tymoszuk U, Pucci A, Finer N, Doyle J, Hashemi M, Elkalaawy M, Adamo M, Jenkinson A, Batterham RL (2016) Reported appetite, taste and smell changes following Roux-en-Y gastric bypass and sleeve gastrectomy: Effect of gender, type 2 diabetes and relationship to post-operative weight loss. Appetite 107:93-105.

Matsutani S, Yamamoto N (2008) Centrifugal innervation of the mammalian olfactory bulb. Anat Sci Int 83:218-227.

Mattson MP (2019) An Evolutionary Perspective on Why Food Overconsumption Impairs Cognition. Trends in Cognitive Sciences 23:200-212.

Mazal PP, Haehner A, Hummel T (2016) Relation of the volume of the olfactory bulb to psychophysical measures of olfactory function. Eur Arch Otorhinolaryngol 273:1-7.

McCrickerd K, Forde CG (2016) Sensory influences on food intake control: moving beyond palatability. Obesity Reviews 17:18-29.

Melis M, Pintus S, Mastinu M, Fantola G, Moroni R, Pepino MY, Tomassini Barbarossa I (2021) Changes of Taste, Smell and Eating Behavior in Patients Undergoing Bariatric Surgery: Associations with PROP Phenotypes and Polymorphisms in the Odorant-Binding Protein OBPIla and CD36 Receptor Genes. Nutrients 13:250.

Midorikawa M, Suzuki H, Suzuki Y, Yamauchi K, Sato H, Nemoto K, Sugano Y, Iwasaki H, Sekiya M, Yatoh S, Yahagi N, Hada Y, Arai T, Shimano H (2021) Relationships between Cognitive Function and Odor Identification, Balance Capability, and Muscle Strength in Middle-Aged Persons with and without Type 2 Diabetes. J Diabetes Res 2021:9961612.

Midroit M, Chalençon L, Renier N, Milton A, Thevenet M, Sacquet J, Breton M, Forest J, Noury N, Richard M, Raineteau O, Ferdenzi C, Fournel A, Wesson DW, Bensafi M, Didier A, Mandairon $N$ (2021) Neural processing of the reward value of pleasant odorants. Current Biology. 
Millman DJ, Murthy VN (2020) Rapid Learning of Odor-Value Association in the Olfactory Striatum. J Neurosci 40:4335-4347.

Min J-Y, Min K-B (2018) Insulin resistance and the increased risk for smell dysfunction in US adults. The Laryngoscope 128:1992-1996.

Miranda MI (2012) Taste and odor recognition memory: the emotional flavor of life. Reviews in the Neurosciences 23:481-499.

Moffett RC, Docherty NG, le Roux CW (2021) The altered enteroendocrine reportoire following rouxen-Y-gastric bypass as an effector of weight loss and improved glycaemic control. Appetite 156:104807.

Moran DT, Rowley JC, Jafek BW, Lovell MA (1982) The fine structure of the olfactory mucosa in man. J Neurocytol 11:721-746.

Mori K, Sakano H (2011) How is the olfactory map formed and interpreted in the mammalian brain? Annu Rev Neurosci 34:467-499.

Morquecho-Campos P, de Graaf K, Boesveldt S (2020) Smelling our appetite? The influence of food odors on congruent appetite, food preferences and intake. Food Quality and Preference $85: 103959$.

Münzberg H, Laque A, Yu S, Rezai-Zadeh K, Berthoud H-R (2015) Appetite and body weight regulation after bariatric surgery. Obesity Reviews 16:77-90.

Murphy C, Schubert CR, Cruickshanks KJ, Klein BEK, Klein R, Nondahl DM (2002) Prevalence of Olfactory Impairment in Older Adults. JAMA 288:2307-2312.

Myers MG, Leibel RL, Seeley RJ, Schwartz MW (2010) Obesity and leptin resistance: distinguishing cause from effect. Trends in Endocrinology \& Metabolism 21:643-651.

Naka A, Riedl M, Luger A, Hummel T, Mueller CA (2010) Clinical significance of smell and taste disorders in patients with diabetes mellitus. Eur Arch Otorhinolaryngol 267:547-550.

Nance K, Acevedo MB, Pepino MY (2020) Changes in taste function and ingestive behavior following bariatric surgery. Appetite 146:104423.

Naznin F, Toshinai K, Waise TMZ, NamKoong C, Md Moin AS, Sakoda H, Nakazato M (2015) Dietinduced obesity causes peripheral and central ghrelin resistance by promoting inflammation. J Endocrinol 226:81-92.

Negoias S, Croy I, Gerber J, Puschmann S, Petrowski K, Joraschky P, Hummel T (2010) Reduced olfactory bulb volume and olfactory sensitivity in patients with acute major depression. Neuroscience 169:415-421.

Nettore IC, Maione L, Palatucci G, Dolce P, Franchini F, Ungaro P, Belfiore A, Colao A, Macchia PE (2020) Flavor identification inversely correlates with body mass index (BMI). Nutrition, Metabolism and Cardiovascular Diseases 30:1299-1305.

Obrebowski A, Obrebowska-Karsznia Z, Gawliński M (2000) Smell and taste in children with simple obesity. Int J Pediatr Otorhinolaryngol 55:191-196. 
O'Brien PD, Hinder LM, Callaghan BC, Feldman EL (2017) Neurological consequences of obesity. The Lancet Neurology 16:465-477.

O'Neill S, O'Driscoll L (2015) Metabolic syndrome: a closer look at the growing epidemic and its associated pathologies. Obesity Reviews 16:1-12.

O'Rahilly S (1998) Life without leptin. Nature 392:330-331.

Padmanabhan K, Osakada F, Tarabrina A, Kizer E, Callaway EM, Gage FH, Sejnowski TJ (2019) Centrifugal Inputs to the Main Olfactory Bulb Revealed Through Whole Brain CircuitMapping. Front Neuroanat 12.

Palouzier-Paulignan B, Lacroix M-C, Aimé P, Baly C, Caillol M, Congar P, Julliard AK, Tucker K, Fadool DA (2012) Olfaction Under Metabolic Influences. Chem Senses 37:769-797.

Pastor A, Fernández-Aranda F, Fitó M, Jiménez-Murcia S, Botella $C$, Fernández-Real JM, Frühbeck G, Tinahones FJ, Fagundo AB, Rodriguez J, Agüera Z, Langohr K, Casanueva FF, Torre R de la (2016) A Lower Olfactory Capacity Is Related to Higher Circulating Concentrations of Endocannabinoid 2-Arachidonoylglycerol and Higher Body Mass Index in Women. PLOS ONE 11:e0148734.

Patel JM, Swanson J, Ung K, Herman A, Hanson E, Ortiz-Guzman J, Selever J, Tong Q, Arenkiel BR (2019) Sensory perception drives food avoidance through excitatory basal forebrain circuits Palmiter RD, Dulac C, Palmiter RD, Knight ZA, eds. eLife 8:e44548.

Patel ZM, DelGaudio JM, Wise SK (2015) Higher Body Mass Index Is Associated with Subjective Olfactory Dysfunction. Behavioural Neurology 2015:e675635.

Patterson DS, Turner P, Smart JV (1966) Smell threshold in diabetes mellitus. Nature 209:625.

Peng M, Coutts D, Wang T, Cakmak YO (2019) Systematic review of olfactory shifts related to obesity. Obesity Reviews 20:325-338.

Peyron C, Tighe DK, Pol AN van den, Lecea L de, Heller HC, Sutcliffe JG, Kilduff TS (1998) Neurons Containing Hypocretin (Orexin) Project to Multiple Neuronal Systems. J Neurosci 18:999610015.

Pierre K, Parent A, Jayet P-Y, Halestrap AP, Scherrer U, Pellerin L (2007) Enhanced expression of three monocarboxylate transporter isoforms in the brain of obese mice. The Journal of Physiology 583:469-486.

Pisarska-Adamczyk M, Tylec P, Gajewska N, Wierzbicka J, Przęczek K, Małczak P, Wysocki M, Pędziwiatr M, Wierdak M, Major P (2021) Postoperative Olfaction Alteration Following Laparoscopic Bariatric Surgery. Journal of Clinical Medicine 10:1704.

Poessel M, Breuer N, Joshi A, Pampel A, Villringer A, Hummel T, Horstmann A (2020a) Reduced Olfactory Bulb Volume in Obesity and Its Relation to Metabolic Health Status. Front Hum Neurosci 14.

Poessel M, Freiherr J, Wiencke K, Villringer A, Horstmann A (2020b) Insulin Resistance Is Associated with Reduced Food Odor Sensitivity across a Wide Range of Body Weights. Nutrients 12:2201. 
Price JL (1985) Beyond the primary olfactory cortex: olfactory-related areas in the neocortex, thalamus and hypothalamus. Chemical Senses 10:239-258.

Price JL, Slotnick BM, Revial M-F (1991) Olfactory projections to the hypothalamus. J Comp Neurol 306:447-461.

Prud'homme MJ, Lacroix MC, Badonnel K, Gougis S, Baly C, Salesse R, Caillol M (2009) Nutritional status modulates behavioural and olfactory bulb Fos responses to isoamyl acetate or food odour in rats: roles of orexins and leptin. Neuroscience 162:1287-1298.

Renner B, Mueller CA, Dreier J, Faulhaber S, Rascher W, Kobal G (2009) The candy smell test: A New Test for Retronasal Olfactory Performance. The Laryngoscope 119:487-495.

Richardson BE, Vander Woude EA, Sudan R, Thompson JS, Leopold DA (2004) Altered Olfactory Acuity in the Morbidly Obese. OBES SURG 14:967-969.

Riera CE, Tsaousidou E, Halloran J, Follett P, Hahn O, Pereira MMA, Ruud LE, Alber J, Tharp K, Anderson CM, Brönneke H, Hampel B, Filho CD de M, Stahl A, Brüning JC, Dillin A (2017) The Sense of Smell Impacts Metabolic Health and Obesity. Cell Metabolism 26:198-211.e5.

Rivière S, Soubeyre V, Jarriault D, Molinas A, Léger-Charnay E, Desmoulins L, Grebert D, Meunier N, Grosmaitre X (2016) High Fructose Diet inducing diabetes rapidly impacts olfactory epithelium and behavior in mice. Scientific Reports 6:34011.

Rolls BJ, Rolls ET, Rowe EA, Sweeney K (1981) Sensory specific satiety in man. Physiology \& Behavior 27:137-142.

Rombaux P, Mouraux A, Bertrand B, Nicolas G, Duprez T, Hummel T (2006) Olfactory Function and Olfactory Bulb Volume in Patients with Postinfectious Olfactory Loss. The Laryngoscope 116:436-439.

Rossi H, Broadhurst K, Luu A, Lara O, Kothari S, Mohapatra D, Recober A (2016) Abnormal trigeminal sensory processing in obese mice. Pain 157:235-246.

Rothemund Y, Preuschhof C, Bohner G, Bauknecht HC, Klingebiel R, Flor H, Klapp BF (2007) Differential activation of the dorsal striatum by high-calorie visual food stimuli in obese individuals. Neuroimage 37:410-421.

Ruiz de Azua I, Martin-Garcia E, Domingo-Rodriguez L, Aparisi Rey A, Pascual Cuadrado D, Islami L, Turunen P, Remmers F, Lutz B, Maldonado R (2021) Cannabinoid CB1 receptor in dorsal telencephalic glutamatergic neurons drives overconsumption of palatable food and obesity. Neuropsychopharmacol 46:982-991.

Russo C, Russo A, Pellitteri R, Stanzani S (2018) Ghrelin-containing neurons in the olfactory bulb send collateralized projections into medial amygdaloid and arcuate hypothalamic nuclei: neuroanatomical study. Exp Brain Res 236:2223-2229.

Sanke H, Mita T, Yoshii H, Someya Y, Yamashiro K, Shimizu T, Ohmura C, Onuma T, Watada H (2021) Olfactory dysfunction predicts the development of dementia in older patients with type 2 diabetes. Diabetes Research and Clinical Practice 174:108740.

Sanke H, Mita T, Yoshii H, Yokota A, Yamashiro K, Ingaki N, Onuma T, Someya Y, Komiya K, Tamura Y, Shimizu T, Ohmura C, Kanazawa A, Fujitani Y, Watada H (2014) Relationship between 
olfactory dysfunction and cognitive impairment in elderly patients with type 2 diabetes mellitus. Diabetes Research and Clinical Practice 106:465-473.

Saper CB, Chou TC, Elmquist JK (2002) The Need to Feed: Homeostatic and Hedonic Control of Eating. Neuron 36:199-211.

Savigner A, Duchamp-Viret P, Grosmaitre X, Chaput M, Garcia S, Ma M, Palouzier-Paulignan B (2009) Modulation of spontaneous and odorant-evoked activity of rat olfactory sensory neurons by two anorectic peptides, insulin and leptin. J Neurophysiol 101:2898-2906.

Schneider NY, Chaudy S, Epstein AL, Viollet C, Benani A, Pénicaud L, Grosmaître X, Datiche F, Gascuel $J(2020)$ Centrifugal projections to the main olfactory bulb revealed by transsynaptic retrograde tracing in mice. Journal of Comparative Neurology 528:1805-1819.

Schubert CR, Cruickshanks KJ, Nondahl DM, Klein BEK, Klein R, Fischer ME (2013) Association of exercise with lower long-term risk of olfactory impairment in older adults. JAMA Otolaryngol Head Neck Surg 139:1061-1066.

Seraj JM, Seraj SM, Zakeri H, Bidar Z, Hashemi S, Parsa FM, Yazdani N (2015) Olfactory Dysfunction in Iranian Diabetic Patients. Acta Medica Iranica:204-206.

Shepherd GM (2006) Smell images and the flavour system in the human brain. Nature 444:316-321.

Shibata M, Mondal MS, Date Y, Nakazato M, Suzuki H, Ueta Y (2008) Distribution of orexinscontaining fibers and contents of orexins in the rat olfactory bulb. Neuroscience Research 61:99-105.

Ship JA, Pearson JD, Cruise L, Brant L, Metter EJ (1996) Longitudinal Changes in Smell Identification. The Journals of Gerontology: Series A 51A:M86-M91.

Shipley MT, Ennis M, Puche AC (2004) CHAPTER 29 - Olfactory System. In: The Rat Nervous System (Third Edition) (Paxinos G, ed), pp 923-964. Burlington: Academic Press.

Simchen U, Koebnick C, Hoyer S, Issanchou S, Zunft H-J (2006) Odour and taste sensitivity is associated with body weight and extent of misreporting of body weight. Eur J Clin Nutr 60:698-705.

Skrandies W, Zschieschang R (2015) Olfactory and gustatory functions and its relation to body weight. Physiology \& Behavior 142:1-4.

Sladek CD, Michelini LC, Stachenfeld NS, Stern JE, Urban JH (2015) Endocrine-Autonomic Linkages. In: Comprehensive Physiology, pp 1281-1323. American Cancer Society.

Soleimanzad H, Smekens F, Peyronnet J, Juchaux M, Lefebvre O, Bouville D, Magnan C, Gurden H, Pain F (2019) Multiple speckle exposure imaging for the study of blood flow changes induced by functional activation of barrel cortex and olfactory bulb in mice. Neurophotonics 6:015008.

Soria-Gómez E et al. (2014a) The endocannabinoid system controls food intake via olfactory processes. Nature Neuroscience 17:407-415. 
Soria-Gómez E, Bellocchio L, Marsicano G (2014b) New insights on food intake control by olfactory processes: The emerging role of the endocannabinoid system. Molecular and Cellular Endocrinology 397:59-66.

Sorokowska A, Schoen K, Hummel C, Han P, Warr J, Hummel T (2017) Food-Related Odors Activate Dopaminergic Brain Areas. Front Hum Neurosci 11.

Stafford LD, Welbeck K (2011) High Hunger State Increases Olfactory Sensitivity to Neutral but Not Food Odors. Chemical Senses 36:189-198.

Stafford LD, Whittle A (2015) Obese Individuals Have Higher Preference and Sensitivity to Odor of Chocolate. Chemical Senses 40:279-284.

Takase K, Tsuneoka Y, Oda S, Kuroda M, Funato H (2016) High-fat diet feeding alters olfactory-, social-, and reward-related behaviors of mice independent of obesity. Obesity 24:886-894.

Terral G, Busquets-Garcia A, Varilh M, Achicallende S, Cannich A, Bellocchio L, Bonilla-Del Río I, Massa F, Puente N, Soria-Gomez E, Grandes P, Ferreira G, Marsicano G (2019) CB1 Receptors in the Anterior Piriform Cortex Control Odor Preference Memory. Current Biology 29:2455-2464.e5.

Thaler JP, Yi C-X, Schur EA, Guyenet SJ, Hwang BH, Dietrich MO, Zhao X, Sarruf DA, Izgur V, Maravilla KR, Nguyen HT, Fischer JD, Matsen ME, Wisse BE, Morton GJ, Horvath TL, Baskin DG, Tschöp $\mathrm{MH}$, Schwartz MW (2012) Obesity is associated with hypothalamic injury in rodents and humans. J Clin Invest 122:153-162.

Thanos PK, Ramalhete RC, Michaelides M, Piyis YK, Wang G-J, Volkow ND (2008) Leptin receptor deficiency is associated with upregulation of cannabinoid 1 receptors in limbic brain regions. Synapse 62:637-642.

Thiebaud N, Gribble F, Reimann F, Trapp S, Fadool DA (2019) A unique olfactory bulb microcircuit driven by neurons expressing the precursor to glucagon-like peptide 1. Sci Rep 9:15542.

Thiebaud N, Johnson MC, Butler JL, Bell GA, Ferguson KL, Fadool AR, Fadool JC, Gale AM, Gale DS, Fadool DA (2014) Hyperlipidemic diet causes loss of olfactory sensory neurons, reduces olfactory discrimination, and disrupts odor-reversal learning. J Neurosci 34:6970-6984.

Thiebaud N, Llewellyn-Smith IJ, Gribble F, Reimann F, Trapp S, Fadool DA (2016) The incretin hormone glucagon-like peptide 1 increases mitral cell excitability by decreasing conductance of a voltage-dependent potassium channel. J Physiol (Lond) 594:2607-2628.

Thomann PA, Dos Santos V, Seidl U, Toro P, Essig M, Schröder J (2009) MRI-Derived Atrophy of the Olfactory Bulb and Tract in Mild Cognitive Impairment and Alzheimer's Disease. Journal of Alzheimer's Disease 17:213-221.

Tichansky DS, Boughter JD, Madan AK (2006) Taste change after laparoscopic Roux-en-Y gastric bypass and laparoscopic adjustable gastric banding. Surgery for Obesity and Related Diseases 2:440-444.

Tong J, Mannea E, Aimé P, Pfluger PT, Yi C-X, Castaneda TR, Davis HW, Ren X, Pixley S, Benoit S, Julliard K, Woods SC, Horvath TL, Sleeman MM, D'Alessio D, Obici S, Frank R, Tschöp MH (2011) Ghrelin enhances olfactory sensitivity and exploratory sniffing in rodents and humans. J Neurosci 31:5841-5846. 
Trellakis S, Tagay S, Fischer C, Rydleuskaya A, Scherag A, Bruderek K, SchlegI S, Greve J, Canbay AE, Lang S, Brandau S (2011) Ghrelin, leptin and adiponectin as possible predictors of the hedonic value of odors. Regulatory Peptides 167:112-117.

Tschöp M, Weyer C, Tataranni PA, Devanarayan V, Ravussin E, Heiman ML (2001) Circulating Ghrelin Levels Are Decreased in Human Obesity. Diabetes 50:707-709.

Tschritter O, Machicao F, Stefan N, Schäfer S, Weigert C, Staiger H, Spieth C, Häring H-U, Fritsche A (2006) A new variant in the human Kv1.3 gene is associated with low insulin sensitivity and impaired glucose tolerance. J Clin Endocrinol Metab 91:654-658.

Tucker K, Cavallin MA, Jean-Baptiste P, Biju KC, Overton JM, Pedarzani P, Fadool DA (2010) The Olfactory Bulb: A Metabolic Sensor of Brain Insulin and Glucose Concentrations via a VoltageGated Potassium Channel. Results Probl Cell Differ 52:147-157.

Tucker K, Overton JM, Fadool DA (2012a) Diet-induced obesity resistance of Kv1.3-/- mice is olfactory bulb dependent. J Neuroendocrinol 24:1087-1095.

Tucker KR, Godbey SJ, Thiebaud N, Fadool DA (2012b) Olfactory ability and object memory in three mouse models of varying body weight, metabolic hormones, and adiposity. Physiology \& Behavior 107:424-432.

Turetsky BI, Moberg PJ, Yousem DM, Doty RL, Arnold SE, Gur RE (2000) Reduced Olfactory Bulb Volume in Patients With Schizophrenia. AJP 157:828-830.

Uchida N, Poo C, Haddad R (2014) Coding and transformations in the olfactory system. Annu Rev Neurosci 37:363-385.

Ueno M, Akiguchi I, Naiki H, Fujibayashi Y, Fukuyama H, Kimura J, Kameyama M, Takeda T (1991) The persistence of high uptake of serum albumin in the olfactory bulbs of mice throughout their adult lives. Archives of Gerontology and Geriatrics 13:201-209.

Wakimoto P, Block G (2001) Dietary Intake, Dietary Patterns, and Changes With Age: An Epidemiological Perspective. The Journals of Gerontology: Series A 56:65-80.

Ward ZJ, Bleich SN, Cradock AL, Barrett JL, Giles CM, Flax C, Long MW, Gortmaker SL (2019) Projected U.S. State-Level Prevalence of Adult Obesity and Severe Obesity. New England Journal of Medicine 381:2440-2450.

Weinstock RS, Wright HN, Smith DU (1993) Olfactory dysfunction in diabetes mellitus. Physiology \& Behavior 53:17-21.

Yamashita T, Murakami T, lida M, Kuwajima M, Shima K (1997) Leptin Receptor of Zucker Fatty Rat Performs Reduced Signal Transduction. Diabetes 46:1077-1080.

Yang Y, Shields GS, Guo C, Liu Y (2018) Executive function performance in obesity and overweight individuals: A meta-analysis and review. Neurosci Biobehav Rev 84:225-244.

Yazla S, Özmen S, Kıyıcı S, Yıldız D, Haksever M, Gencay S (2018) Evaluation of olfaction and taste function in type 2 diabetic patients with and without peripheral neuropathy. Diabetes/Metabolism Research and Reviews 34:e2973.

Yeomans MR (2006) Olfactory influences on appetite and satiety in humans. Physiol Behav 89:10-14. 
Yilmaz Y, Polat S, Yildiz M, Turgut SB, Topal N, Aydin B, Onal H, Tekeli H, Doty RL (2019) Sense of smell and quality of life in children with diabetes mellitus. International Journal of Pediatric Otorhinolaryngology 123:43-46.

Zaghloul H, Pallayova M, Al-Nuaimi O, Hovis KR, Taheri S (2018) Association between diabetes mellitus and olfactory dysfunction: current perspectives and future directions. Diabetic Medicine 35:41-52.

Zandt EE in 't, Cansler HL, Denson HB, Wesson DW (2019) Centrifugal Innervation of the Olfactory Bulb: A Reappraisal. eNeuro 6:ENEURO.0390-18.2019.

Zhang Y, Proenca R, Maffei M, Barone M, Leopold L, Friedman JM (1994) Positional cloning of the mouse obese gene and its human homologue. Nature 372:425-432.

Zhang Z, Liu Q, Wen P, Zhang J, Rao X, Zhou Z, Zhang H, He X, Li J, Zhou Z, Xu X, Zhang X, Luo R, Lv G, $\mathrm{Li} \mathrm{H}$, Cao P, Wang L, Xu F (2017) Activation of the dopaminergic pathway from VTA to the medial olfactory tubercle generates odor-preference and reward. Elife 6.

Zhang Z, Zhang B, Wang X, Zhang X, Yang QX, Qing Z, Lu J, Bi Y, Zhu D (2018) Altered Odor-Induced Brain Activity as an Early Manifestation of Cognitive Decline in Patients With Type 2 Diabetes. Diabetes 67:994-1006.

Zhang Z, Zhang B, Wang X, Zhang X, Yang QX, Qing Z, Zhang W, Zhu D, Bi Y (2019) Olfactory Dysfunction Mediates Adiposity in Cognitive Impairment of Type 2 Diabetes: Insights From Clinical and Functional Neuroimaging Studies. Diabetes Care 42:1274-1283.

Zhou Y, Wang X, Cao T, Xu J, Wang D, Restrepo D, Li A (2017) Insulin Modulates Neural Activity of Pyramidal Neurons in the Anterior Piriform Cortex. Front Cell Neurosci 11.

Zizzari P, He R, Falk S, Bellocchio L, Allard C, Clark S, Lesté-Lasserre T, Marsicano G, Clemmensen C, Perez-Tilve D, Finan B, Cota D, Quarta C (2021) CB1 and GLP-1 Receptors Cross Talk Provides New Therapies for Obesity. Diabetes 70:415-422.

Zsoldos I, Sinding C, Godet A, Chambaron S (2021) Do Food Odors Differently Influence Cerebral Activity Depending on Weight Status? An Electroencephalography Study of Implicit Olfactory Priming Effects on the Processing of Food Pictures. Neuroscience 460:130-144. 